\title{
An integrated "omics" approach to the characterization of maize (Zea mays L.) mutants deficient in the expression of two genes encoding cytosolic glutamine synthetase
}

Nardjis Amiour ${ }^{1}$, Sandrine Imbaud², Gilles Clément ${ }^{1}$, Nicolas Agier ${ }^{2,4,5}$, Michel Zivy ${ }^{3}$, Benoît Valot ${ }^{3}$, Thierry Balliau ${ }^{3}$, Isabelle Quilleré ${ }^{1}$, Thérèse Tercé-Laforgue ${ }^{1}$, Céline Dargel-Graffin ${ }^{1}$ and Bertrand Hirel ${ }^{1^{*}}$

\begin{abstract}
Background: To identify the key elements controlling grain production in maize, it is essential to have an integrated view of the responses to alterations in the main steps of nitrogen assimilation by modification of gene expression. Two maize mutant lines ( $\ln 1.3$ and $g \ln 1.4)$, deficient in two genes encoding cytosolic glutamine synthetase, a key enzyme involved in nitrogen assimilation, were previously characterized by a reduction of kernel size in the gln 1.4 mutant and by a reduction of kernel number in the gln 1.3 mutant. In this work, the differences in leaf gene transcripts, proteins and metabolite accumulation in $g / n 1.3$ and $g / n 1.4$ mutants were studied at two key stages of plant development, in order to identify putative candidate genes, proteins and metabolic pathways contributing on one hand to the control of plant development and on the other to grain production.

Results: The most interesting finding in this study is that a number of key plant processes were altered in the gln 1.3 and gln 1.4 mutants, including a number of major biological processes such as carbon metabolism and transport, cell wall metabolism, and several metabolic pathways and stress responsive and regulatory elements. We also found that the two mutants share common or specific characteristics across at least two or even three of the "omics" considered at the vegetative stage of plant development, or during the grain filling period.

Conclusions: This is the first comprehensive molecular and physiological characterization of two cytosolic glutamine synthetase maize mutants using a combined transcriptomic, proteomic and metabolomic approach. We find that the integration of the three "omics" procedures is not straight forward, since developmental and mutant-specific levels of regulation seem to occur from gene expression to metabolite accumulation. However, their potential use is discussed with a view to improving our understanding of nitrogen assimilation and partitioning and its impact on grain production.
\end{abstract}

Keywords: Assimilation, Glutamine synthetase, Grain filling, Maize, Metabolome, Mutant, Nitrogen, Proteome, Transcriptome, Yield

\footnotetext{
*Correspondence: hirel@versailles.inra.fr

${ }^{1}$ Institut Jean-Pierre Bourgin, Institut National de la Recherche Agronomique (INRA), Centre de Versailles-Grignon, Unité Mixte de Recherche 1318 INRA-Agro-ParisTech, Equipe de Recherche Labellisée, Centre National de la Recherche Scientifique 3559, RD10, F-78026 Versailles, Cedex, France Full list of author information is available at the end of the article
} 


\section{Background}

Over the last two decades, there has been considerable interest in improving nitrogen use efficiency (NUE) in model and crop plants using quantitative genetic approaches [1], mainly because attempts to engineer plant $\mathrm{N}$ metabolism have on most occasions, only met with limited success [2,3]. The aim of such studies based on the construction of genetic maps and then QTL detection, has been to identify chromosomal regions involved in the control of yield and its components and to determine the relative importance of high or low nitrogen $(\mathrm{N})$ fertilisation $[4,5]$. Thus, exploiting the genetic variability of grain yield and grain quality traits under N-limiting or non-limiting conditions appeared to be a key target for improving NUE. More recently, a number of quantitative genetic studies performed mostly on rice and maize, were conducted to detect QTLs for the nutritional quality of grain or stover (amino acids, protein, oil and starch content) as a function of $\mathrm{N}$ fertilisation [6-9].

In other quantitative studies aimed at identifying the genetic basis of NUE, in addition to agronomic traits, the association of metabolic and physiological functions with DNA markers was also investigated [10-12].

As for the agronomic traits, a significant genotypic variation was observed for various physiological traits measured in young developing leaves related to $\mathrm{N}$ metabolism. In particular, coincidences of QTLs for yield and its components with genes encoding cytosolic glutamine synthetase (GS1) and the corresponding enzyme activity were detected, which could partially explain the variations in yield. Since a QTL for a thousand kernel weight was coincident with a cytosolic GS (Gln1.4) locus, and QTLs for a thousand kernel weight and yield were coincident with another cytosolic GS (Gln1.3) locus [10], further work was undertaken to validate the function of these two putative candidate genes. In subsequent studies, it was also shown that the corresponding GS1.3 isoenzyme is present in the leaf mesophyll cells, whereas the GS1-4 isoenzyme is specifically localized in the leaf bundle sheath cells. In addition, it was found that in maize leaves among the five different cytosolic isoenzymes, GS1.3 and GS1.4 are the most highly expressed irrespective of the plant developmental stage [13]. Thus, the impact of the knockout mutations $g \ln 1.3$ and $g \ln 1.4$ on kernel yield and its components were examined in plants grown under non-limiting $\mathrm{N}$ feeding conditions [13]. The phenotypes of the two mutant lines were characterized by a reduction of kernel size in the $g \ln 1.4$ mutant and by a reduction of kernel number in the gln1.3 mutant. Transgenic plants that overexpressed Gln1.3 constitutively in the leaves, exhibited an increase in kernel number, thus providing further evidence that the GS1.3 isoenzyme plays a major role in controlling kernel yield under high [13] or low $\mathrm{N}$ fertilisation conditions [1].
The hypothesis that GS is one of the key steps in the control of cereal productivity was strengthened by a study performed on rice, in which a co-localization of a QTL for the GS1.1 locus and a QTL for one-spikelet weight was identified [14]. As a confirmation, a strong reduction in growth rate and kernel yield was observed in rice mutants deficient in GS1.1 [15].

In order to improve our knowledge of the physiological and molecular responses of two maize mutants deficient in the expression of Gln1.3 and Gln1.4, an analysis of the leaf metabolome was conducted in parallel with a proteomic and a transcriptomic study at the vegetative stage and in the middle of the grain filling period, representing key physiological and developmental stages during the life cycle of the plant. These studies provide an integrated view of the biological responses of the mutant plants, spanning from gene expression and protein content to metabolite accumulation. The possibility that these traits can be used as investigative tools to identify candidate genes for grain production, in relation to plant growth and development, is discussed.

\section{Results and discussion}

Changes in leaf metabolite profile of $g \ln 1.3$ and $g \ln 1.4$ mutants

In the present study, GC/MS analysis of the leaf metabolome was performed using WT, gln1.3 and $g \ln 1.4$ mutant plants grown on a high $\mathrm{N}$ supply. Samples were taken at two key stages of plant development: the leaf vegetative stage (V) and 55 days after silking, referred to as leaf maturity $(\mathrm{M})$, as described in Methods. At the V stage, during which young developing maize leaves efficiently assimilate $\mathrm{CO}_{2}$ through the $\mathrm{C}_{4}$ photosynthetic pathway and inorganic $\mathrm{N}$ for amino acid and protein synthesis [16], extensive differences were observed in metabolite accumulation between the two GS mutants in comparison to the WT (Additional file 1: Table S1).

At the $\mathrm{V}$ stage in the leaves of the $g \ln 1.3$ mutant, among the 48 identified metabolites that showed statistically significant differences compared to the WT in the three replicates $(P \leq 0.05)$, the concentrations of most of the soluble amino acids (14 out of 22), as well as a number of soluble sugars and sugar alcohols, were strongly reduced by 2 to 500 fold. The amount of the polyamine putrescine was also lower in comparison to the WT.

In the leaves of the $g \ln 1.4$ mutant, 13 metabolites were present in lower concentrations, as compared to the WT. These metabolites included various $\mathrm{C}$ containing molecules and some precursors of lignin biosynthesis such as coumaroylquinate, quinate, and shikimate, the content of the latter two being also lower in the $g \ln 1.3$ mutant. In addition, as determined in the $g \ln 1.3$ mutant, lower amounts of the polyamine putrescine were detected in $g \ln 1.4$, whilst leucine was the only amino acid 
that exhibited a decrease. Lower amounts of carbohydrates such as galactose, sedoheptulose and sugar alcohols such as erythritol, were also detected in both $g \ln 1.3$ and $g \ln 1.4$. All together, these results show that at the $\mathrm{V}$ stage and irrespective of the GS mutation, there is a decrease in the accumulation of a set of metabolites (green background in Additional file 1: Table S1).

In the leaves of the $g \ln 1.3$ mutant, a significant increase was observed in the content of a number of organic acids involved in the tricarboxylic acid (TCA) cycle, notably malate, 2-oxoglutarate, fumarate and aconitate. Such an increase was only observed in the $g \ln 1.4$ mutant, for malate alone. One possible explanation for this finding could be that in $g \ln 1.3$, there is an accumulation of molecules that are normally used as carbon skeletons for the synthesis of amino acids. In particular these would be the amino acids derived from glutamine and glutamate that are presumably synthesized at a much lower rate when the activity of the GS1.3 isoenzyme is reduced. Interestingly, the sinapinate content of $g \ln 1.3$ was around 19 times higher compared to the WT, suggesting that part of the lignin biosynthesis pathway had been severely altered, since phenylpropanoid metabolism is extremely dependent on the $\mathrm{N}$ status of the plant [17]. An increase in the concentrations of raffinose, rhamnose, galactinol, mannitol and maltose has previously been observed in $\mathrm{N}$-deficient maize plants [18]. The increase in inositol, a molecule related to stress conditions and involved in the control of plant growth [19], is an interesting finding, which suggests that the metabolic response caused by the lack of the GS1.3 isoenzyme is similar to that found for other abiotic stresses $[20,21]$. The increase in such a range of metabolites probably occurs partly at the expense of the precursor glucose, since the increases were less in the gln1.3 mutant, a situation similar to that also found under $\mathrm{N}$ limiting conditions [18]. The increase in the vitamin nicotinate, a stress protective molecule [22] and malonate, a defence compound [23], further supports the hypothesis that the partial lack of GS activity mimics stress conditions. Moreover, such stress conditions are likely to lower the demand for the respiration of alternative substrates such as 2hydroxyglutarate [24], a molecule that accumulates almost five fold in the $g \ln 1.3$ mutant.

In the $g \ln 1.4$ mutant, the number of metabolites exhibiting an increase in their amount was much lower compared to $g \ln 1.3$. Phenylalanine was one of the most interesting, as its accumulation probably occurred to avoid feedback inhibition of the corresponding biosynthetic pathway [25]. Such an accumulation of phenyalanine could explain why there is a decrease in the accumulation of its precursor shikimate, or its derivates coumaroylquinate and quinate, both molecules being precursors of lignin biosynthesis [26].

From the metabolite profile at the $\mathrm{V}$ stage, it would appear that the impact of the gln1.3 mutation was much greater than that of the $g \ln 1.4$ mutation. Such a finding is logical, since it has been shown that the gene encoding the GS1.3 isoenzyme is constitutively expressed irrespective of the leaf developmental stage, whilst the expression of the gene encoding the GS1.4 isoenzyme is much lower and only enhanced at later stages of leaf development [16]. Moreover, it is well known that a lack of $\mathrm{N}$ assimilates such as amino acids before the flowering period, as observed in the metabolic profile of the $g \ln 1.3$ mutant, can cause ovule abortion [27]. Consequently, there is a reduction in the grain number of the $g \ln 1.3$ mutant [13]. At the M stage, the metabolite profiles of leaves below the ear in the two GS mutants were very different compared to the leaves of plants at the V stage. The only exceptions were metabolites such as aconitate, rhamnose and malate, which exhibited an opposite pattern of accumulation, depending on the plant developmental stage, or the GS mutation (in bold characters in Additional file 1: Table S1). Less than half of the metabolites (22 out of 48) exhibited differences in their concentration in the $g \ln 1.3$ mutant between the $\mathrm{M}$ and the $\mathrm{V}$ stage. In contrast, in the gln 1.4 mutant, the number of metabolites exhibiting an altered level of accumulation was similar between the two stages of plant development (44 for $\mathrm{V}$ and 52 for $\mathrm{M}$ ). However, in the gln1.4 mutant, the number of metabolites exhibiting an increase in concentration was three times higher at the $\mathrm{M}$ stage, compared to that found at the V stage ( 15 at $\mathrm{M}$ and 5 at V; Additional file 1: Table S1). As discussed above for the $\mathrm{V}$ stage, this could be related to the fact that the GS1.4 isoenzyme is preferentially involved in the grain filling process at the later M stage of plant development [13].

At the $\mathrm{M}$ stage, there was still a reduction in the amount of organic acids of the TCA cycle, but this was limited to aconitate in the $g \ln 1.3$ mutant. In the $g \ln 1.4$ mutant, the amount of malate and other organic acids derived from the TCA cycle such as citramalate and glucarate were reduced. At the grain filling stage in the $g \ln 1.3$ mutant, decreases in the amounts of several other soluble carbohydrates such as melibiose, arabinose and glycerolipids such as galactosylglycerol were observed. A considerable decrease in the amount of galactarate was detected in the $\operatorname{gln} 1.3$ mutant. This decrease was much less in the gln1.4 mutant. The biosynthesis and physiological roles of a number of the metabolites listed above have not been clearly defined and further work is required to identify their role in plants in relation to stress in general [28], and N-deficiency stress in particular. The 3-fold increase in the amount of phosphoenolpyruvate, fructose and glucose in the $g \ln 1.3$ mutant only, indicates that during the grain filling period, a large proportion of the $\mathrm{C}$ molecules fuelling the TCA cycle were not used or were exported. This presumably results from an alteration in the sink capacity of the plant characterised by the considerable reduction in grain number [13]. 
In the $g \ln 1.4$ mutant, an increase in the concentration of coumarate and caffeate, two precursors of lignin that were not detected at the V stage, suggests that an alteration in cell wall synthesis or composition, also occurred at the $M$ stage. Interestingly, in the $g \ln 1.3$ mutant, the decrease in the amino acids observed at the $\mathrm{V}$ stage was not detected at the $\mathrm{M}$ stage. In contrast, the $g \ln 1.4 \mathrm{mu}$ tant, in which the amino acid content was not modified at the $\mathrm{V}$ stage, exhibited a 2 to 3 fold increase in valine, serine, threonine, methionine, aspartate, alanine and glutamate at the $M$ stage. Since we showed previously that the synthesis of a number of these amino acids still occurred at the M stage in WT plants [18], it is likely that their accumulation (glutamate in particular) is due to the lack of GS1.4 activity during the grain filling period. As these amino acids are not exported to the grain until this $M$ stage of plant development, there is a reduction in grain size in the gln1.4 mutant [13], as $\mathrm{N}$ translocation is required to fill the grain $[29,30]$. However, it cannot be completely ruled out that the amino acids could be exported to the grain at a later stage of development.

\section{Changes in the leaf proteome of the $g \ln 1.3$ and $g \ln 1.4$ mutants}

At the V stage, when the leaf proteome of the WT was compared with the $g \ln 1.3$ and $g \ln 1.4$ mutants, 46 protein spots were identified as exhibiting significant differences in their volume $(\mathrm{p}<0.05)$ in the former and 14 proteins in the latter. The densitometric quantification of these differences is presented in Additional file 1: Tables S2 and S4. At the $M$ stage, the volumes of 51 protein spots were significantly modified in the gln1.3 mutant, whereas only 28 proteins were modified in the $g \ln 1.4$ mutant (Additional file 1: Tables S3 and S5).

At the V stage, among the 46 identified proteins in the $g \ln 1.3$ mutant, 29 were present at lower and 17 at higher concentrations. These proteins are involved in a variety of physiological processes including $\mathrm{C}$ assimilation, photosynthesis, cell wall metabolism, proteolysis, stress/defence mechanisms and translation. In the $g \ln 1.4$ mutant the same biological processes were altered, however compared to the $g \ln 1.3$ mutant, there were much fewer proteins present in lower (10 proteins) or higher amounts (4 proteins). Therefore, it can be concluded that at the protein accumulation level, the impact of the $g \ln 1.3$ mutation was much stronger than that of $g \ln 1.4$.

One of the most interesting results from the proteomic study performed at the $\mathrm{V}$ stage, was the stronger impact of the $g \ln 1.3$ mutation compared to the $g \ln 1.4$ mutation on the accumulation of proteins involved in $\mathrm{C}$ assimilation and $C$ metabolism, whereas those involved in $\mathrm{N}$ metabolism displayed no changes in their level of accumulation. It was also observed that among the 29 proteins present in lower amounts in the gln1.3 mutant,
8 of the same proteins were also found to be present in lower amounts in the gln1.4 mutant (Table 1). Such findings suggest that at the proteomic level the two GS mutations had a similar impact on a number of biological processes. In particular, the decrease in amount of the enzymes ribose-5-phosphate isomerase [31] and NADPdependent malate dehydogenase [32] suggests that the pentose phosphate pathway and the $\mathrm{C}_{4}$ photosynthetic pathway respectively, were down-regulated in response to the lower flux of reduced $\mathrm{N}$ going through the reaction catalysed by GS1.3 or GS1.4. In addition, the finding that peroxiredoxin and glutaredoxin (CAXIP1 also called GrxS14) were less abundant in the two GS mutants indicates that redox signals [33] and oxidative stress responses [34], in relation to photosynthesis, were also altered. In line with the finding that $\mathrm{C}$ metabolism and some of its associated processes were modified in the two GS mutants, an accumulation of the translation initiation factor IF3, a protein that is an important component of the regulation of photosynthetic gene expression [35], was also detected.

At the $M$ stage, the differences in protein profiles of the two GS mutants were not the same as those detected at the V stage. Although in $g \ln 1.3$, three proteins were found to be present either in higher or lower amounts at both stages of plant development (protein names in italics in Additional file 1: Tables S2 and S3). In the gln1.3 mutant and to a lesser extent in the gln1.4 mutant, the changes observed in the protein profiles at the $M$ stage indicate that the main metabolic functions involved were related to photosynthesis and to $\mathrm{C}$ metabolism. Proteins involved in the efficiency of the photosystems and the glycolytic, pentose phosphate and starch biosynthesis pathways were present in much lower quantities. Interestingly a significant number of these proteins such as phosphoribulokinase, and NADP-specific isocitrate dehydrogenase (Table 1), exhibited a common pattern of accumulation in the two GS mutants. Such findings, in line with the accumulation of metabolites, suggest that, during the grain-filling period, the lower flux of $\mathrm{N}$ going through the reaction catalysed by GS triggers a reduction in $\mathrm{C}$ assimilation, likely because the sink capacity of the plant in terms of $C$ translocation to the developing ear is strongly reduced. Surprisingly, lower amounts of the enzyme glyceraldehyde-3-phosphate dehydrogenase were detected in the gln1.4 mutant, whereas in $g \ln 1.3$ there was an accumulation of the protein. Such contradictory patterns of accumulation could be related to the stress-responsive nature of the enzyme [36], which appears to be specific for each $g \ln 1.3$ and $g \ln 1.4$ mutation.

In addition, among the proteins exhibiting a decrease in their amount in the two GS mutants, there were two isoforms of the enzyme arginine decarboxylase. This result suggests that polyamine biosynthesis was modified in $g \ln 1.3$ and $g \ln 1.4$ presumably in response to the stress 
Table 1 Proteins detected in lower and higher amounts in the gln 1.3 and $g \ln 1.4$ mutants as compared to the wild type

\begin{tabular}{|c|c|c|}
\hline Identification number & Function/pathway & Lower amount at the $\mathrm{V}$ stage \\
\hline TC463245 & Ammonia assimilation & Glutamine synthetase root isozyme 3 (GS1-3) \{Zm\} P38561 \\
\hline TC467371 & $\mathrm{C}_{4}$ carbon metabolism & Malate dehydrogenase $[N A D P]$, chloroplast precursor E $\{Z m\}$ P15719 \\
\hline TC294877 & Oxidative stress & CAXIP1-like protein $\{$ At $\}$ AY157989 \\
\hline TC288041 & Pentose phosphate & Ribose-5-phosphate isomerase precursor \{So\} Q8RU73 \\
\hline TC287751 & Proteolysis & ATP-dependent protease $\{\mathrm{OS}\}$ Q50LH5 \\
\hline TC524782 & Redox signalling & Peroxiredoxin-2E-2, chloroplast precursor $\{\mathrm{Os}\}$ Q69TY4 \\
\hline TC287421 & Translation & $60 S$ acidic ribosomal protein P2B $\{Z m\} 024415$ \\
\hline \multirow[t]{2}{*}{ TC310278 } & Translation & Eukaryotic translation initiation factor 5A \{Zm\} P80639 \\
\hline & & Higher amount at the $\mathrm{V}$ stage \\
\hline \multirow[t]{2}{*}{ TC499661 } & Translation & 'Translation initiation factor IF-3-like Q6K674 \\
\hline & & Lower amount at the $M$ stage \\
\hline TC279798 & Abiotic stress & DnaK-type molecular chaperone hsp70 \{Os\} Q53NM9 \\
\hline TC312072 & Chloroplast structure & Plastid-lipid-associated protein 3 \{Os\} Q7XBW5 \\
\hline TC279235 & Development & Actin $1\{0 \mathrm{~s}\}$ A2XLF2 \\
\hline TC304992 & Glycolysis & Fructose-bisphosphate $\{$ Os\} aldolase Q69V57 \\
\hline TC286949 & Organic acid synthesis & NADP-specific isocitrate dehydrogenase $\{\mathrm{O}\}$ Q9XGU8 \\
\hline TC283000 & Oxidative stress & Peroxidase J $\{$ Os\} Q7F1U1 \\
\hline TC281878 & Pathogen defence & Hairpin binding protein $1\{Z \mathrm{~m}\}$ Q5QJA2 \\
\hline TC293364 & Pentose phosphate & 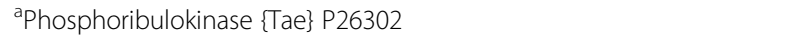 \\
\hline TC305088 & Pentose phosphate & Transketolase $\{Z \mathrm{Zm}\}$ Q7SIC9 \\
\hline TC293364 & Pentose phosphate & aPhosphoribulokinase \{Tae\} P26302 \\
\hline TC292245 & Photosynthesis/Calvin cycle & 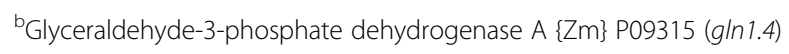 \\
\hline TC303207 & Polyamine biosynthesis & Arginine decarboxylase $\{\mathrm{Os}\}$ Q01HV9 \\
\hline TC304817 & Redox signalling & 2-Cys peroxiredoxin BAS1 \{OS\} Q6ER94 \\
\hline TC312398 & Signalling & Tyrosine phosphatase $\{\mathrm{Os}\}$ Q9LKK3 \\
\hline TC311663 & Starch synthesis & Glucose-1-phosphate adenyly|transferase $\{Z \mathrm{Zm}\}$ A5GZ73 \\
\hline TC307030 & Stress/Defence & OSJNBa0006A01.5 protein $\{$ Os\} Q7F9L9 \\
\hline \multirow[t]{2}{*}{ TC310158 } & Translation & Elongation factor 1-delta $1\{$ Os\} Q40680 \\
\hline & & Higher amount at the $M$ stage \\
\hline TC310669 & Photosynthesis/C/N/Metabolism & Ferredoxin $\{Z \mathrm{~m}\}$ Q9SLP5 \\
\hline TC292245 & Photosynthesis/Calvin cycle & ${ }^{\mathrm{b}}$ Glyceraldehyde-3-phosphate dehydrogenase A \{Zm\} P09315 (gln 1.3) \\
\hline TC293513 & Stress/Defence & Chaperonin CPN60-2, mitochondrial precursor \{Zm\} Q43298 \\
\hline
\end{tabular}

asoforms of the same protein exhibiting a different level of accumulation.

${ }^{\mathrm{b}}$ Protein showing an opposite pattern of accumulation in $g \ln 1.3$ and $g \ln 1.4$.

caused by the reduction in leaf GS activity. The involvement of polyamines during abiotic stress [37] is in line with the finding that the putrescine and spermidine contents were decreased or increased respectively in the GS mutants (see Additional file 1: Table S1). The presence of higher or lower amounts of a number of oxidative stress-responsive proteins, such as peroxidases, superoxide dismutase, peroxiredoxins as well as various biotic and abiotic stress-responsive proteins, was evident either in both, or only one of the two GS mutants (Table 1 and Additional file 1: Tables S3 and S4).
At the $\mathrm{M}$ and $\mathrm{V}$ stages, the common set of proteins that were down-regulated and up-regulated in $g \ln 1.3$ and $g \ln 1.4$ were different (Table 1). This result suggests that in the two GS mutants there is a core set of proteins corresponding to different biological processes that are specifically altered at each of the two developmental stages examined. As in a number of proteomic studies related to plant stress (see [38] for a review), relatively few proteins exhibited significant differences in their level of accumulation in the two GS mutants. Reduced GS activity altered the accumulation of proteins and enzymes involved in 
photosynthesis, primary $\mathrm{C}$ metabolism and stress-related regulatory mechanisms, a plant response similar to that observed under $\mathrm{N}$ deficient conditions [39-41,18].

\section{Correlations between the two gln 1 mutations, mRNA accumulation and a variety of metabolic, signalling and developmental processes}

At the $\mathrm{V}$ stage, 106 and 52 mRNA transcripts were present in lower amounts in the leaves of the $g \ln 1.3$ and the $g \ln 1.4$ mutants respectively, when compared to the WT. (Additional file 1: Tables S6a and S8a). The biological processes most significantly reduced in the two $g \ln 1$ mutants, were $\mathrm{C}$ metabolism, stress/defence, proteolysis, signalling, transport, as well as components of the translation and transcription machinery. In the $g \ln 1.3$ mutant, the reduction in transcript accumulation for ADP-glucose pyrophosphorylase, NAD-malate dehydrogenase, ribulose-5-phosphate 3-epimerase and pyruvate dehydrogenase suggests that, at least at the transcriptional level, important steps of primary $\mathrm{C}$ assimilation were down-regulated (Additional file 1: Table S6a). The high level of pyruvate dehydrogenase kinase mRNA accumulation further supports this hypothesis, as phosphorylation of the pyruvate dehydrogenase complex would reduce enzyme activity and consequently the $\mathrm{C}$ flux through the TCA cycle [42]. Another important impact of the $g \ln 1.3$ mutation was a decrease in the amount of transcripts encoding proteins involved in sugar and amino acid transport, which suggests that the translocation and thus the subsequent accumulation of a number of $\mathrm{C}$ and $\mathrm{N}$ metabolites may be reduced.

The decrease both in terms of the number of biological processes involved and the portfolio of genes belonging to each of these processes was much higher in the $g \ln 1.3$ mutant compared to the $g \ln 1.4$ mutant. Such findings, in agreement with the metabolomic and proteomic studies, could explain why the impact of the $g \ln 1.3$ mutation, compared to the gln1.4 mutation, was much higher in terms of grain yield penalty [13].

At the V stage, transcripts of 139 genes were present in higher amounts in the $g \ln 1.3$ mutant as compared to the WT (Additional file 1: Table S6b), whereas in the $g \ln 1.4$ mutant there were only 54 (Additional file 1: Table S8b). Transcripts of various genes encoding proteins having different metabolic and signalling roles, in stress/defence, translation, transcription and transport were predominantly represented. Whilst those genes encoding enzymes involved in $\mathrm{C}$ and secondary metabolite metabolism and precursors of cell wall synthesis were present to a lesser extent. Transcripts of asparaginase, which exhibited a strong homology with asparaginase 2 from grasses, were more than three-fold higher in $g \ln 1.3$ than in the WT, otherwise there were no major changes in gene expression of the proteins involved in $\mathrm{N}$ assimilation. Again, the impact of the
GS mutation with respect to the enhanced expression of a number of genes involved in the various functions listed in Additional file 1: Tables S5b and S7b, was much higher in the $g \ln 1.3$ mutant.

A similar pattern of transcript accumulation was observed at the $\mathrm{M}$ stage, both in the $g \ln 1.3$ and $g \ln 1.4 \mathrm{mu}-$ tant. The number of up- and down-regulated genes in the gln1.3 mutant was 133 and 170 respectively, which is quantitatively similar to that detected at the $\mathrm{V}$ stage. In $\operatorname{gln} 1.4$, there was an increase in the expression of 102 genes and a decrease in the expression of 96 genes, indicating that the number of genes with a modified level of expression was approximately two-fold higher compared to the V stage (Additional file 1: Tables S7a, S7b, S9a and $\mathrm{S} 9 \mathrm{~b})$. As identified at the $\mathrm{V}$ stage, the main biological processes that were altered in the $g \ln 1.4$ mutant were metabolism, signalling, stress/defence and transport. However, at the $\mathrm{M}$ stage in comparison to the $\mathrm{V}$ stage, the number of up- or down-regulated genes encoding enzymes involved in $\mathrm{C}$ metabolism was much lower. Interestingly, the number of genes encoding proteins relating to proteolytic activity were significantly increased in the $g \ln 1.4 \mathrm{mu}-$ tant at the $\mathrm{M}$ stage compared to the $\mathrm{V}$ stage (Additional file 1: Table S9b). The hypothesis that the GS1.4 isoenzyme is involved in the recycling of ammonia released during protein degradation [13], may explain the changes observed in the expression of genes encoding various proteases. In line with this observation, it has also been found that protein degradation was enhanced in transgenic plants overexpressing cytosolic GS [43]. As identified at the V stage, the impact of the two GS mutations on genes encoding enzymes and proteins involved in $\mathrm{N}$ assimilation and recycling remained very limited. Such observations lead to the conclusion that in maize, cytoplasmic GS is a central hub at the cross roads of a number of plant metabolic and regulatory functions, other than $\mathrm{N}$ assimilation per se.

In recent "omics"-based studies performed on maize and other species $[44,45,18]$, it has been shown that the plant developmental stage must be taken into account, as there are large differences both at the physiological and molecular levels during the transition from $\mathrm{N}$ assimilation to $\mathrm{N}$ remobilisation $[18,38]$. When maize plants were grown under $\mathrm{N}$-limiting conditions, no decreases or increases in the amounts of transcripts were found that were common to the $V$ and $M$ stage [18]. In contrast, in the two GS mutants, a number of transcripts (70 in $g \ln 1.3$ and 29 in $g \ln 1.4$ ) exhibited a similar pattern of accumulation at both stages of plant development (Additional file 1: Tables S10 and S11). A qRT-PCR experiment performed on four selected genes exhibiting an increase or a decrease in the $g \ln 1.3$ and gln1.4 mutants in comparison to the WT at the V and the $M$ stage of plant development, confirmed that the level of leaf transcript accumulation was similar to that 
observed in the $46 \mathrm{~K}$ microarray experiment (Additional file 1: Figure S1).

A list of selected genes that exhibited a fold change higher than 10 in a mutant compared to the WT is shown in Tables 2 and 3. They could be key candidate genes representative of the reprogramming machinery involved in the control of shoot growth and development in the two mutants, in which only grain yield, but not leaf size or leaf number, was affected [13]. Our study also shows that for a number of key metabolic pathways such as the primary assimilation of $\mathrm{C}$ and $\mathrm{N}$, major changes could occur in terms of metabolite accumulation as shown in the present study (see Additional file 1: Table S1), but not at the gene expression level. As previously shown in several investigations, very little direct correspondence between the accumulation of metabolites, proteins and mRNA transcripts has been found in "omics"based studies $[18,46]$. Such a situation is probably due to the complex nature of biological networks and to the fact that both tissue and cellular compartmentation and translocation between different organs, are generally not taken into account (see [47] for a review).

\section{Common changes in key biological functions are found in the $g \ln 1.3$ and $g \ln 1.4$ mutants that are dependent on the plant developmental stage}

A limited number of transcripts exhibited a similar pattern of accumulation in both the $g \ln 1.3$ and $g \ln 1.4$ mutants, suggesting that the decrease in leaf GS1.3 and GS1.4 activity induces a common plant response at the transcriptional level. At the V stage, in both mutants, 11 genes were up-regulated, 2 genes were down-regulated and 2 genes showed an opposite pattern of expression. (Additional file 1: Table S12). At the M stage, 19 genes were up-regulated, 19 genes were down-regulated and 2 genes showed an opposite pattern of expression (Additional file 1: Table S13). Interestingly in both mutants, transcripts for a $40 \mathrm{~S}$ and $60 \mathrm{~S}$ ribosomal protein showed an opposite pattern of accumulation at the $\mathrm{V}$ stage and the $\mathrm{M}$ stage respectively.

In a similar manner to the proteomic changes, the responses in transcript accumulation could provide clues as to how the plant maintains normal vegetative growth when sink organs such as the grain do not develop and thereby import less $\mathrm{C}$ and $\mathrm{N}$ assimilates. At the $\mathrm{V}$ stage in the two GS mutants, the massive accumulation (more than 400 fold compared to the WT) of Muscular LMNAInteracting Protein (MLIP) 15 mRNAs encoding a Leucine Zipper Transcription Factor (bZIP) involved in abiotic stress tolerance [48], suggests that this protein is a major stress-responsive element induced in response to the lack of cytosolic GS activity. A $23 \mathrm{kDa}$ photosystem II protein was also highly up-regulated with more than a 200-fold increase in mRNA accumulation in the two mutants. When GS activity is reduced, the photosynthetic products are not used for grain filling and it is then possible that there is excess light, which exceeds the requirement of the plant to assimilate $\mathrm{CO}_{2}$. Consequently, the light energy needs to be dissipated as thermal energy through an increase in the synthesis and repair of the pigment antenna of photosystem II $[49,50]$.

The accumulation of transcripts for isoleucyl-tRNA synthetase in the two GS mutants is intriguing. Although the role of this enzyme is well established in lower organisms, the information on its role in higher plants is scarce. Based on the results obtained in microorganisms [51,52], it is attractive to think that there are some important posttranscriptional modifications resulting from the lack of the GS1.3 and GS1.4 isoenzyme, which could modify gene codon recognition and thus the protein sequence. The increase in the steady state level of mRNA encoding a putative mannitol transporter is also an interesting result. It is well established that such a monosaccharide transporter is involved in a variety of biological processes related to phloem function, resource allocation, plant defence and sugar signalling [53].

Compared to the V stage, there was a clear balance between the up- and down-regulated genes at the M stage. Among the most strongly up-regulated genes (more than 60-fold), one encoding a cytochrome P450 monoxygenase CYP72A27 (which can be subjected to transposition and then act as a retrotransposon [54]) was particularly interesting. Moreover, this type of enzyme can be involved in the synthesis of secondary metabolites that could be used as precursors of compounds such as lignin [55]. The changes in the accumulation of secondary metabolites observed in a previous study [56] and in the present investigation (see Table 4 and Additional file 1: Table S1), also indicate that lignin biosynthesis was altered, thus possibly affecting shoot structure and ear development [57]. In agreement with this hypothesis, a gene encoding a putative cinnamoyl-CoA reductase, the first enzyme after the branch of the lignin biosynthetic pathway [58], was also up-regulated. The strong accumulation of transcripts for a glycoside hydrolase, an enzyme involved in cell wall polysaccharide metabolism [59] and the considerable decrease in the amount of mRNA for an acid chitinase [60], further support the hypothesis that there was some readjustment in the production of a number of structural compounds during plant growth and development. The increase in the amount of transcripts encoding an allene oxide cyclase is more difficult to interpret, but it is possible that an abiotic stress response mediated by jasmonic acid [61] is induced when the GS1.3 and GS1.4 isoenzymes are not active. In addition to the number of metabolic and regulatory roles altered in the two GS mutants, an important reprogramming of translational and post-translational activity is likely to occur at the same time, since a number of 
Table 2 Transcripts exhibiting a large increase or decrease in the $g \ln 1.3$ and $g \ln 1.4$ mutants at the $V$ stage as compared to the wild type

\begin{tabular}{|c|c|c|c|}
\hline Identification number & Functional category & Putative annotation & FC/WT \\
\hline \multicolumn{4}{|l|}{ gln 1.3 mutant } \\
\hline TC255750 & Transcription & MLIP $15\{Z m\}$ Q41833 & 430.37 \\
\hline TC260113 & Photosynthesis & 23 kDa polypeptide of photosystem II \{Nt\} Q04126 & 283.37 \\
\hline TC253688 & Transposon & Transposase $\{Z m\}$ Q5UDR1 & 43.62 \\
\hline TC261195 & Proteolysis & 265 proteasome regulatory subunit-like protein $\{\mathrm{Os}\} \mathrm{Q69Q88}$ & 34.37 \\
\hline TC250399 & Signalling & Pyruvate dehydrogenase kinase isoform $2\{Z \mathrm{~m}\} \mathrm{O} 82424$ & 30.98 \\
\hline TC278448 & C metabolism & Phosphoribulokinase precursor $\{\mathrm{O}$ s\} P26302 & 29.41 \\
\hline TC251968 & Secondary metabolism & Chalcone isomerase-like $\{\mathrm{Os}\} \mathrm{Q6EQW} 2$ & 28.12 \\
\hline TC270988 & Signalling & Protein phosphatase type-2C \{Zm\} Q9FQY2 & 23.61 \\
\hline TC253650 & Transport & Putative nitrite transporter $\{\mathrm{O}$ s $\}$ Q5Z6P7 & 22.38 \\
\hline TC276810 & Signalling & Putative calcium binding protein $\{\mathrm{Os}\}$ Q652U8 & 22.14 \\
\hline TC271736 & Translation & Ribosomal protein S21-like protein \{Os\} Q6YUV4 & 18.77 \\
\hline AZM4_72986 & Nuclesome assembly & Histone H2B.2 \{Zm\} P30756 & 17.14 \\
\hline TC264476 & Transcription & MA3 domain-containing protein $\{\mathrm{O}\}$ Q10PT6 & 14.19 \\
\hline TC249105 & Metabolism & Ferredoxin $1\{Z m\}$ P27787 & 13.43 \\
\hline TC279125 & Cell wall & Hydroxyproline-rich glycoprotein-like protein \{Os\} Q67UA8 & 12.36 \\
\hline TC264087 & Stress/Defence & AvrRpt2-induced protein 2-like \{Os\} Q6Z2W4 & 11.97 \\
\hline TC277283 & Cell wall & Glycoside hydrolase family 28 protein $\{\mathrm{Os}\}$ Q10B12 & 11.37 \\
\hline TC252426 & Lipid metabolism & 3-hydroxybutyryl-CoA dehydrogenase-like protein $\{$ At\} Q9LDF5 & 11.03 \\
\hline TC213118 & Metabolism & Sesquiterpene cyclase $\{Z \mathrm{~m}\}$ Q9FEF5 & 10.69 \\
\hline TC270254 & Metabolism & Putative mitochondrial F0 ATP synthase D chain \{Os\} Q9FT52 & 10.54 \\
\hline BM382459 & C metabolism & NAD-malate dehydrogenase precursor $\{\mathrm{Nt}\} \mathrm{Q} 9 \mathrm{XQP4}$ & 0.07 \\
\hline AZM4_41292 & C metabolism & ADP-glucose pyrophosphorylase small subunit \{Zm\} Q947C0 & 0.05 \\
\hline TC192492 & Signalling & Peptidyl-prolyl cis-trans isomerase $\{\mathrm{O}\}$ A2WYA7 & 0.04 \\
\hline TC256186 & Transport & Putative integral membrane protein $\{\mathrm{Os}\}$ Q688W0 & 0.02 \\
\hline \multicolumn{4}{|l|}{ gln 1.4 mutant } \\
\hline TC260113 & Photosynthesis & 23-kDa polypeptide photosystem II \{Nt\} Q04126 & 200.22 \\
\hline TC266788 & Metabolism & Putative NADPH HC toxin reductase $\{\mathrm{O}\}$ Q7X6N6 & 107.17 \\
\hline TC199171 & Proteolysis & Putative uncharacterized protein $\{\mathrm{O} s\}$ Q75K52 & 67.99 \\
\hline TC259563 & Transport & Ubiquinol-cytochrome C reductase complex ubiquinone-binding protein \{Os\} Q9LDS7 & 65.76 \\
\hline TC272126 & Translation & Putative uncharacterized protein $\{$ Ps\} A9NTN5 & 60.23 \\
\hline BM380216 & Cell wall & Glycine-rich cell wall structural protein precursor $\{$ At\} P27483 & 36.64 \\
\hline TC266666 & Metabolism & NAD dependent epimerase/dehydratase family protein $\{\mathrm{O}\}$ Q10CW5 & 24.91 \\
\hline TC195262 & Stress/Defence & Isoleucyl-tRNA synthetase-like \{Os\} Q67WM1 & 23.25 \\
\hline TC270988 & Signalling & Protein phosphatase type-2C \{Zm\} Q9FQY2 & 21.34 \\
\hline CD990526 & Stress/Defence & Lipoate biosynthesis-LIP5 \{Os\} O48673 & 15.74 \\
\hline TC200462 & Unknown & Putative uncharacterized protein $\{\mathrm{Os}\}$ Q75IJ0 & 13.59 \\
\hline TC260627 & Unknown & Putative uncharacterized protein $\{$ Sb\} Q8LKT8 & 13.00 \\
\hline TC259358 & Signalling & Type 2 non specific lipid transfer protein precursor $\{$ Tae\} Q2PCC5 & 12.57 \\
\hline TC262845 & Signalling & MAP kinase $4\{Z m\}$ Q9ZWJ6 & 11.55 \\
\hline AZM4_8141 & Transport & Putative lipid transfer protein $\{O s\}$ AZM4_8141 & 0.09 \\
\hline TC262118 & C Metabolism & Putative aldose reductase $\{\mathrm{Os}\}$ QODHM8 & 0.09 \\
\hline TC250487 & C metabolism & Putative trehalose-6-phosphate synthase $\{$ At\} Q9C9W6 & 0.08 \\
\hline
\end{tabular}


Table 2 Transcripts exhibiting a large increase or decrease in the $g \ln 1.3$ and $g \ln 1.4$ mutants at the $V$ stage as compared to the wild type (Continued)

\begin{tabular}{lll}
\hline TC265311 & Stress/Defence & DnaJ protein homolog-like $\{$ Os $\}$ Q6YT03 \\
TC217530 & Transcription & Homeodomain leucine zipper protein $16\{$ Os $\}$ Q6Q502 \\
BM380114 & Transposon & Transition Protein-TNP2 $\{$ Os $\}$ Q948C7 \\
TC198868 & Stress/Defence & Putative interferon-related protein $\{$ Os $\}$ Q6ZIP6 \\
CF637160 & Translation & 60S acidic ribosomal protein P3 $\{Z m\}$ O24413 \\
TC197759 & Stress/Defence & rRNA N-glycosidase $\{Z \mathrm{Zm}\}$ Q41851
\end{tabular}

FC/WT corresponds to the fold change in the mutants compared to wild type (WT) leaves for transcripts exhibiting significant variations (Student $\mathrm{t}$-test, $P \leq 0.05)$ in their amount.

transcripts encoding ribosomal proteins and a RNA recognition motif protein [62] were present in larger amounts in both the $g \ln 1.3$ and $g \ln 1.4$ mutants. It is also worth noting that a number of genes of unknown function exhibited an altered level of expression.

\section{Integrated view of the differences in accumulation of metabolites, proteins and transcripts}

As in a previous study aimed at integrating the three different "omics" investigations when maize plants were grown under N-limiting conditions [18], we have made a similar attempt to integrate the transcriptome, proteome and metabolome datasets and the impact of the two $g \ln 1$ mutations at two key stages of plant development. Such an integrated "omics" picture can provide important information on the impact of the two $g \ln 1$ mutations on the physiological adaptation of the plant. Irrespective of their biological functions, the quantitative differences observed in mRNA transcript, protein and metabolite accumulation in relation to the plant developmental stage are presented in Table 4 . In addition, the relative importance of these processes in terms of number of metabolites, proteins and transcripts exhibiting differences within common functional categories across the three "omic" studies is presented in Figure 1. The most important differences were generally observed at the transcript accumulation level, regardless of the plant developmental stage.

Fewer variations in functional diversity were observed at the metabolome level, although changes in $\mathrm{C}$ and $\mathrm{N}$ metabolites and to a lesser extent secondary metabolites, precursors of cell wall synthesis, were the main consequences of the $g \ln 1.3$ and $g \ln 1.4$ mutations (see also Additional file 1: Table S1). Nevertheless, it is clear that the process that is the most strongly affected in the two gln 1 mutants is $\mathrm{C}$ metabolism, irrespective of the mutation and of the plant developmental age. Important changes in the accumulation of leaf $\mathrm{C}$ metabolites, mostly represented by soluble sugars, sugar alcohols and organic acids were the main consequences of $\mathrm{N}$ deficiency [18], a metabolic signature that is similar to that described here in the two GS mutants (Table 4). Such a finding is consistent with the now established hypothesis that the reaction catalysed by the enzyme GS is the major route facilitating the incorporation of inorganic $\mathrm{N}$ into organic molecules [63,64].

Interestingly, the $g \ln 1.3$ mutation had only a limited impact on $\mathrm{N}$ metabolism across the three "omics" components, both at the $\mathrm{V}$ and the $\mathrm{M}$ plant developmental stage. In the $g \ln 1.4$ mutant, simultaneous changes in metabolites, proteins and transcript accumulation related to $\mathrm{N}$ assimilation and recycling were only observed at the $M$ stage. This observation is consistent with the finding that the bundle sheath-specific GS1.4 isoform is encoded by a gene induced during leaf aging, which plays a catabolic role in the reassimilation of ammonium released during protein degradation in senescing leaves at the $M$ stage [13].

In a similar manner to the $\mathrm{N}$-deficient growth conditions investigated by [18], in at least two of the three "omics" experiments, the synthesis of cell wall components, as well as stress and defence mechanisms were altered in the two GS mutants. These alterations include the accumulation of marker metabolites for stress conditions, which agrees with the observation that $\mathrm{C}$ metabolism, lignin biosynthesis and stress-responsive elements are coordinately regulated [65]. Although throughout the plant life cycle, both at the transcriptome and proteome level, a number of stress-responsive elements and plant defence mechanisms specific for the plant developmental stage were up- or down-regulated in the two GS mutants (Table 2), in a similar manner to when $\mathrm{N}$ is limiting [18].

Differences in the protein profile of the two GS mutants in comparison to the WT were relatively minor, again comparable with the impact of $\mathrm{N}$ limitation on the leaf proteome [18]. Moreover these proteins were involved in a limited number of plant biological functions. One explanation is that some of the low-abundance structural, or regulatory proteins cannot be detected using 2-D gel electrophoresis in comparison to a maize pan-transcriptome. It is also possible that the decrease in GS1 activity, may involve a number of post-translational protein modifications that were not investigated in the present study. It is likely that such post-translational modifications occur in the leaf proteome of the GS mutants, since two different protein 
Table 3 Transcripts exhibiting a large increase or decrease in $g \ln 1.3$ mutant at the $M$ stage as compared to the wild type

\begin{tabular}{|c|c|c|c|}
\hline Identification number & Functional category & Putative annotation & FC/WT \\
\hline TC250399 & Signalling & Pyruvate dehydrogenase kinase isoform $2\{\mathrm{Zm}\} \mathrm{O} 82424$ & 157.42 \\
\hline Al065741 & Stress/Defence & Thaumatin-like cytokinin-binding protein $\{\mathrm{OS}\}$ Q2QND8 & 47.43 \\
\hline TC251968 & Secondary metabolism & Chalcone isomerase-like $\{\mathrm{O}$ s $\mathrm{Q} 6 \mathrm{EQW} 2$ & 44.04 \\
\hline TC264087 & Stress/Defence & AvrRpt2-induced protein 2-like \{Os\} Q6Z2W4 & 35.66 \\
\hline TC260211 & Lipid metabolism & ${ }^{\mathrm{a}}$ Allene oxide cyclase $\{\mathrm{Zm}\}$ Q6RW09 & 33.17 \\
\hline TC271736 & Translation & Ribosomal protein S21-like protein \{Os\} Q6YUV4 & 32.63 \\
\hline TC253688 & Transposition & Transposase $\{Z m\}$ Q5UDR1 & 29.82 \\
\hline TC279125 & Cell wall & Hydroxyproline-rich glycoprotein-like protein $\{\mathrm{O}\}$ \} Q67UA8 & 29.29 \\
\hline AZM4_72986 & Nucelosome assembly & Histone H2B.2 \{Zm\} P30756 & 26.47 \\
\hline Al065444 & Translation & 40 S ribosomal protein S26 \{Os\} P49216 & 23.65 \\
\hline TC277283 & Cell wall & Glycoside hydrolase family 28 protein $\{\mathrm{Os}\}$ Q10B12 & 23.09 \\
\hline TC252413 & Metabolism & Cinnamyl alcohol dehydrogenase $\{L p\}$ Q8S411 & 22.61 \\
\hline TC270142 & Transcription & Auxin response factor $1\{\mathrm{Os}\} \mathrm{Q} 2 \mathrm{QQ} \times 6-2$ & 18.62 \\
\hline TC259350 & Cell wall & Exopolygalacturonase precursor \{Zm\} P35339 & 17.51 \\
\hline TC277223 & Transport & Putative monosaccharide transporter $1\{$ Os\} Q69S90 & 16.03 \\
\hline CF056912 & Transcription & Histone deacetylase $\{Z m\}$ Q9ZTP8 & 14.72 \\
\hline TC276810 & Signalling & Putative calcium binding protein $\{\mathrm{O} s\}$ Q652U8 & 13.63 \\
\hline TC200056 & Secondary metabolism & 4-coumarate-CoA ligase 4CL1 \{Lp\} Q9M7S3 & 12.58 \\
\hline TC251967 & Secondary metabolism & Chalcone isomerase-like $\{\mathrm{O}$ s\} Q6EQW2 & 12.41 \\
\hline TC192449 & Cell wall & Pectate lyase $\{Z m\}$ Q43861 & 12.36 \\
\hline TC271645 & Transport & Chloroplast glucose-6-phosphate/phosphate translocator \{Ps\} A4UTS2 & 11.94 \\
\hline TC270824 & Stress/Defence & Putative shock protein SRC2 \{Os\} Q0JMR3 & 11.76 \\
\hline AW289103 & Cell wall & Exopolygalacturonase precursor $\{Z m\}$ P26216 & 11.61 \\
\hline TC264439 & Signalling & Zinc finger protein family-like $\{\mathrm{OS}\}$ Q6ZKY1 & 10.83 \\
\hline TC271833 & C metabolism & Granule bound starch synthase Ila $\{\mathrm{Zm}\} \mathrm{A} 4 \mathrm{URH} 2$ & 10.80 \\
\hline AZM4_101226 & Metabolism & Ferredoxin $\{Z m\}$ AZM4_101226 & 10.19 \\
\hline TC249219 & Proteolysis & $26 \mathrm{~S}$ proteasome regulatory particle non-ATPase subunit3 \{Os\} Q8W3N4 & 10.12 \\
\hline TC269702 & C metabolism & Arabinogalactan protein $\{\mathrm{Nt}\} \mathrm{Q} 9 \mathrm{FUL8}$ & 10.03 \\
\hline CF633665 & Metabolism & Glycosyltransferase $\{\mathrm{Sb}\}$ Q5QPY7 & 0.09 \\
\hline Al979477 & Transport & Ammonium transporter 1-3 $\{\mathrm{Os}\}$ Q947M9 & 0.09 \\
\hline TC273598 & C metabolism & Beta-glucosidase 31 Os\} B7F7K7 & 0.08 \\
\hline TC273931 & Transport & Putative peptide transport protein $\{\mathrm{Os}\}$ Q7XDJ1 & 0.08 \\
\hline TC207366 & Signalling & Putative calcium-dependent protein kinase $\{\mathrm{Os}\}$ Q61587 & 0.08 \\
\hline TC254765 & Stress/Defence & Glutathione S-transferase GST $34\{Z \mathrm{~m}\}$ Q9FQA5 & 0.07 \\
\hline CF029576 & Transcription & SCARECROW gene regulator, putative related cluster $\{\mathrm{Os}\}$ Q53MB4 & 0.07 \\
\hline TC255650 & Metabolism & Putative trehalose-6-phosphate synthase $\{\mathrm{O}\}$ \} Q6Z548 & 0.06 \\
\hline TC264842 & Stress/Defence & $101 \mathrm{kDa}$ heat shock protein $\{$ Tae\} Q334I0 & 0.05 \\
\hline BG835945 & C metabolism & Putative beta-1,3-glucanase \{Os\} Q6Z9Y9 & 0.04 \\
\hline TC266129 & Transcription & Putative transcription activator RF2a $\{\mathrm{O}$ s\} Q10LT0 & 0.04 \\
\hline
\end{tabular}


Table 3 Transcripts exhibiting a large increase or decrease in $g \ln 1.3$ mutant at the $M$ stage as compared to the wild type (Continued)

\begin{tabular}{lll}
\hline BG458838 & Unknown & Expressed protein \{Os\} Q6AU54 \\
BM501271 & C metabolism & Putative beta-1 3-glucanase $\{$ Os $\}$ Q6Z9Y9 \\
TC266256 & Metabolism & S-adenosylmethionine decarboxylase $\{$ Sa $\}$ A4GXE8 \\
TC271423 & Stress/Defence & Glutathione S-transferase GST 18 $\{$ Zm\} Q9FQC1 \\
AZM4_124731 & Metabolism & Putative P450 monooxygenase $\{$ Os $\}$ BAD09944.1
\end{tabular}

FC/WT corresponds to the fold change in the mutants compared to wild type (WT) leaves for transcripts exhibiting significant variations (Student t-test, $P \leq 0.05)$ in their amount.

spots for the same sequence were identified for the enzyme fructose-bisphosphate aldolase (Additional file 1: Table $\mathrm{S} 2 \mathrm{~b})$ and for ferredoxin (Additional file 1: Table S3b).

\section{Conclusions}

Increasing amounts of "omics" data are available related to the response of both model and crop plants to shortterm and long-term N-deficiency and other abiotic stresses (Simons et al. 2014) [38]. However, linking these data to a plant phenotype in terms of plant growth, development and yield remains a challenge. This is mainly because, as shown in the present study and a number of other recent investigations $[66,67,18]$, when examining individually the biological systems involved, there is only a single level of complexity, which increases when their interactions are considered [68]. Moreover, there is often very little direct correlation between differences in the accumulation of metabolites, proteins and mRNA transcripts [47], due to the complexity inherent in biological networks and to the fact that both tissue and cellular compartmentation within different organs are generally not taken into account. This metabolomic study performed on the $g \ln 1.3$ and $g \ln 1.4$ mutants should also be carried out using labelled molecules in a fluxomic study [69] performed on individual organs harvested at the $\mathrm{V}$ and the $M$ stage.

Nevertheless, the most interesting finding in this study is that in two separate mutants in which a different cytosolic GS isoenzyme has been deleted, a number of major biological processes such as $\mathrm{C}$ metabolism and transport, cell wall metabolism, and several metabolic pathways and stress responsive and regulatory elements, share common or specific characteristics across at least two or even three of the "omics" considered. Some of these biological processes are specific or common to the two GS mutants depending on the plant developmental stage. They are represented in Figure 2 and can be summarized as follow: in the $g \ln 1.3$ mutant the decrease in the accumulation of amino acids occurring during the $\mathrm{V}$ stage is due to a decrease in $\mathrm{N}$ assimilation resulting in a decrease in the number of kernels. During this period, the lack of amino acids induced an accumulation of organic acids that are normally used as $\mathrm{C}$ skeletons for amino acid synthesis, the $\mathrm{N}$ residues being provided by glutamine. An accumulation of stress-responsive metabolites was also observed similar to that which occurred when there is a shortage in N. Since fewer kernels were produced, carbohydrates synthesized, or exported during the grain filling period accumulated in the leaves. In the gln1.4 mutant, the main changes observed in terms of metabolite accumulation mostly occurred during the grain filling period, when the amino acids were released during $\mathrm{N}$ remobilisation. These amino acids were not used to fill the kernels, thus limiting their development. During the grain filling period, an accumulation of cell wall components took place in both GS mutants, which indicates that the reduction in either kernel number or kernel size had strong repercussions on the basic structure of source organs, presumably to circumvent the decrease in storage capacity of the sink organs.

It will be necessary to exploit further "omics" data such as those obtained with the $g \ln 1.3$ and $g \ln 1.4$ mutants, in order to improve our understanding of the source to sink relationship in terms of maize productivity. This can be achieved by linking genes and metabolic functions to physiological or agronomic traits, through the construction of whole genome-scale metabolic models [70,38]. The ultimate goal of developing such models is to provide a new tool for predicting crop yields that will allow the selection of crops adapted to lower inputs and to particular environmental conditions, while maintaining an acceptable yield. The knowledge gained from such modelling approaches could ultimately allow for the identification of key developmental and metabolic components involved in the elaboration of complex agronomic traits such as biomass and grain production.

The "omics" data obtained by growing plants under varying $\mathrm{N}$ conditions and by analysing genetically modified plants and mutants altered in the expression of structural or regulatory genes, can be incorporated in the model even if the genes do not have a direct link with primary $\mathrm{C}$ and $\mathrm{N}$ metabolism. Such data could provide a more accurate simulation of the impact of the genetic alteration on the metabolic interactions and fluxes throughout the plant. Subsequently, such a modelling approach could allow the identification of key reactions controlling plant 
Table 4 Overview of the main changes occurring in a leaf of the gln 1.3 and $g \ln 1.4$ mutants at the metabolome, proteome and transcriptome level

\begin{tabular}{|c|c|c|c|c|c|}
\hline TRANSCRIPTOME & PROTEOME & METABOLOME & TRANSCRIPTOME & PROTEOME & METABOLOME \\
\hline \multicolumn{6}{|c|}{ VEGETATIVE (V) } \\
\hline & Lower in $g \ln 1.3-$ & & & Higher in $g \ln 1.3$ & \\
\hline C METABOLISM (10) & C Metabolism (4) & C METABOLISM (12) & C metabolism (4) & C metabolism (7) & C METABOLISM (14) \\
\hline N metabolism (1) & & N METABOLISM (15) & N metabolism (1) & & \\
\hline CW Metabolism (3) & CW Metabolism (3) & CW Metabolism (2) & CW Metabolism (3) & CW Metabolism (1) & CW Metabolism (1) \\
\hline METABOLISM (20) & Metabolism (5) & Metabolism (1) & METABOLISM (22) & Metabolism (2) & Metabolism (2) \\
\hline Proteolysis $(7)$ & Proteolysis (3) & & Proteolysis (7) & & \\
\hline SIGNALLING (16) & & & SIGNALLING (19) & & \\
\hline STRESS/DEFENCE (10) & Stress /Defence (8) & & STRESS/DEFENCE (25) & Stress/Defence (2) & \\
\hline TRANSPORT (14) & & & TRANSPORT (12) & & \\
\hline Transcription (8) & & & TRANSCRIPTION (10) & & \\
\hline \multirow[t]{2}{*}{ Translation (4) } & Translation (3) & & Translation (8) & Translation (2) & \\
\hline & Lower in $g \ln 1.4$ & & & Higher in $g \ln 1.4$ & \\
\hline \multirow[t]{3}{*}{ C metabolism (2) } & C Metabolism (2) & C METABOLISM (8) & C metabolism (1) & C Metabolism (1) & C METABOLISM (3) \\
\hline & N metabolism (1) & N Metabolism (1) & & & N Metabolism (1) \\
\hline & & CW (3) & & & \\
\hline Metabolism (4) & & & Metabolism (4) & & \\
\hline Proteolysis (1) & Proteolysis (1) & & Proteolysis (3) & & \\
\hline Signalling (7) & & & Signalling (7) & & \\
\hline Stress/Defence (8) & Stress/Defence (2) & & Stress/Defence $(7)$ & Stress/Defence (1) & \\
\hline Transport (3) & & & Transport (6) & & \\
\hline Translation (4) & Translation (2) & & Translation (3) & Translation (2) & \\
\hline \multicolumn{6}{|c|}{ MATURITY (M) } \\
\hline & Lower in $g \ln 1.3$ & & & Higher in $g \ln 1.3-$ & \\
\hline C Metabolism (6) & C METABOLISM (9) & C METABOLISM (12) & C METABOLISM (10) & C Metabolism (5) & C METABOLISM (5) \\
\hline N Metabolism (3) & N metabolism (2) & & N Metabolism (1) & N Metabolism (1) & \\
\hline CW Metabolism (1) & & & CW METABOLISM (22) & CW Metabolism (1) & CW Metabolism (1) \\
\hline METABOLISM (21) & Metabolism (2) & & METABOLISM (15) & Metabolism (5) & Metabolism (3) \\
\hline PROTEOLYSIS (13) & Proteolysis (2) & & Proteolysis (6) & & \\
\hline SIGNALLING (14) & Signalling (1) & & SIGNALLING (20) & & \\
\hline STRESS/DEFENCE (22) & Stress/Defence $(7)$ & & STRESS/DEFENCE (24) & Stress/Defence (2) & \\
\hline TRANSPORT (15) & & & TRANSPORT (16) & Transport (1) & \\
\hline Transcription (7) & & & TRANSCRIPTION (10) & & \\
\hline Translation (3) & Translation (2) & & Translation (8) & Translation (4) & \\
\hline & Lower in $g \ln 1.4$ & & & Higher in $g \ln 1.4$ & \\
\hline C Metabolism (6) & C Metabolism (8) & C Metabolism (5) & C Metabolism (5) & & C Metabolism (3) \\
\hline CW Metabolism (1) & & CW Metabolism (1) & CW Metabolism (1) & & CW Metabolism (2) \\
\hline N Metabolism (4) & N metabolism (2) & N Metabolism (2) & N Metabolism (2) & & N Metabolism (7) \\
\hline METABOLISM (13) & & Metabolism (3) & METABOLISM (18) & Metabolism (1) & Metabolism (3) \\
\hline Proteolysis (7) & & & Proteolysis (4) & & \\
\hline SIGNALLING (12) & Signalling (1) & & SIGNALLING (13) & & \\
\hline STRESS/DEFENCE (12) & Stress/Defence (7) & & STRESS/DEFENCE (11) & Stress/Defence (4) & \\
\hline
\end{tabular}


Table 4 Overview of the main changes occurring in a leaf of the $g \ln 1.3$ and $g \ln 1.4$ mutants at the metabolome, proteome and transcriptome level (Continued)

\begin{tabular}{|c|c|}
\hline Transport (9) & TRANSPORT (10) \\
\hline Transcription (8) & Transcription (8) \\
\hline Translation (6) & Translation (7) \\
\hline
\end{tabular}
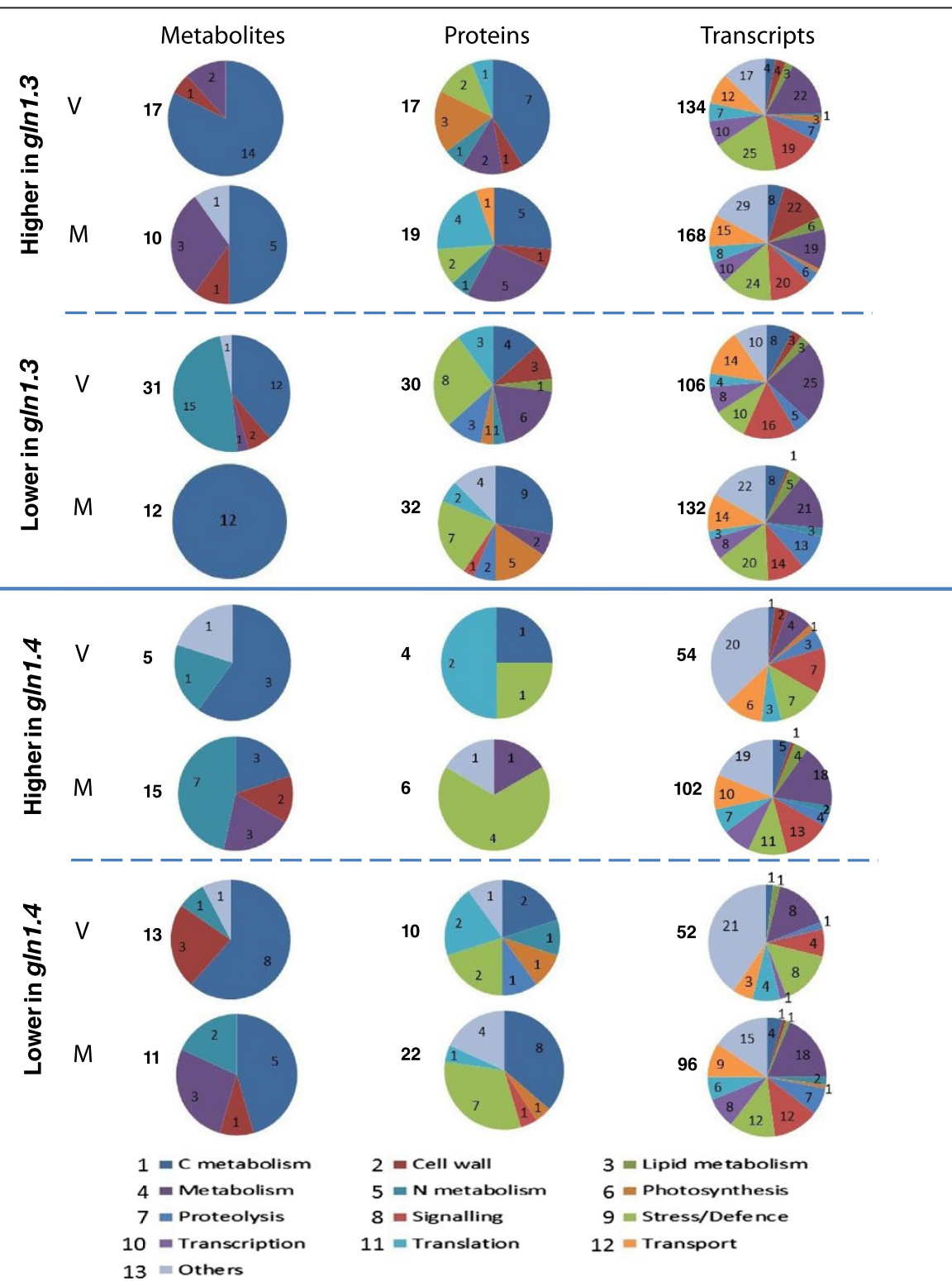

Figure 1 Functional categories of metabolites, proteins and gene transcripts isolated from the leaves of maize $g \ln 1.3$ and $g \ln 1.4$ mutant plants, exhibiting differences in their level of accumulation. Pie charts show the number of metabolites, proteins and transcripts for each functional class identified in the three "omics" experiments exhibiting an increase or a decrease in the leaves of the gln 1.3 and gln 1.4 mutants at the vegetative $(V$ and mature $(M)$ stage of leaf development. For each mutant and each developmental stage, the total number of changes is indicated on the left side of the pie chart. 


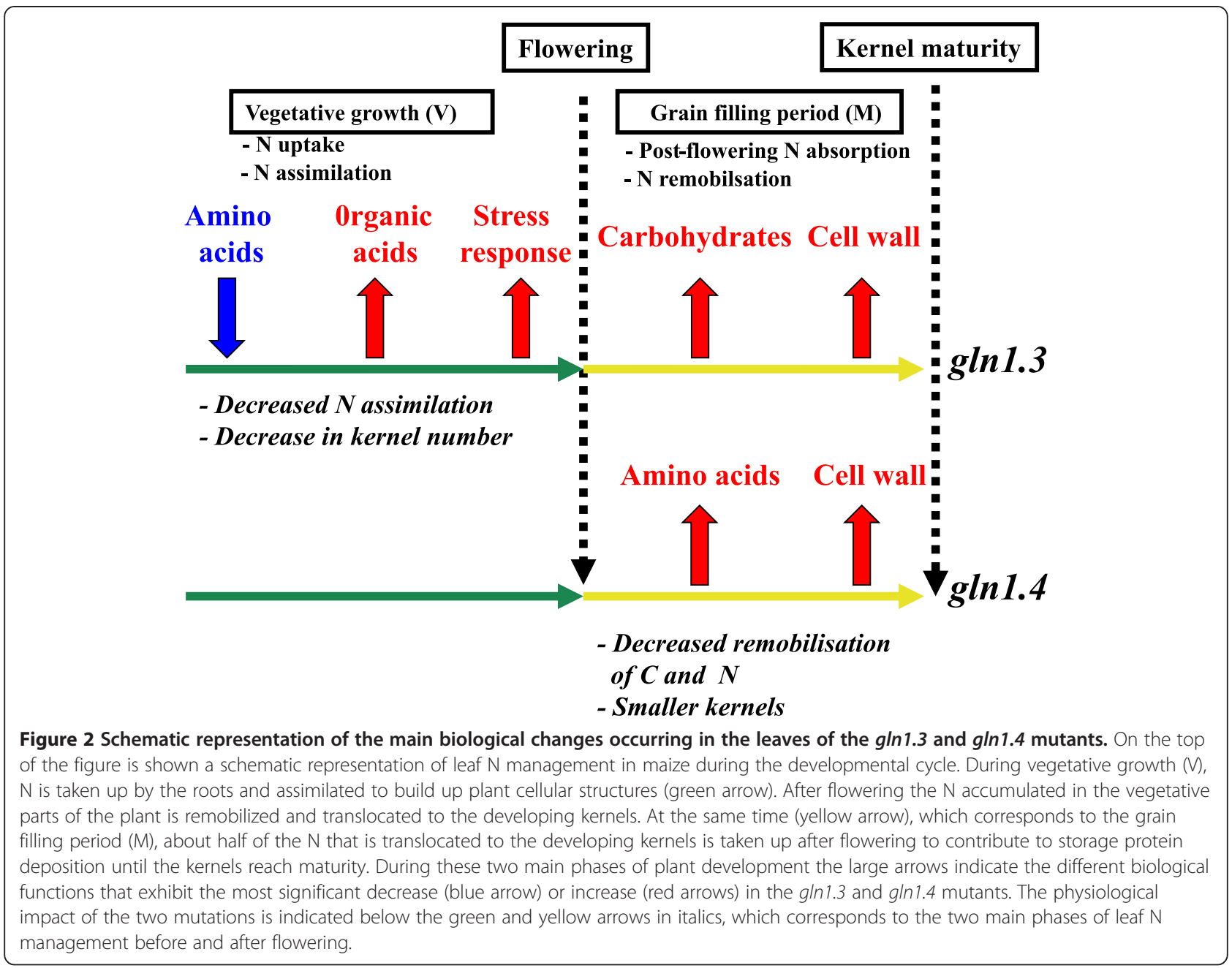

growth and development under different $\mathrm{N}$ fertilisation or stress conditions [38].

Furthermore, the genes identified in the transcriptome studies, which were found to be the most strongly upor down-regulated in the present investigation (listed in Tables 2 and 3), can be placed on a maize genetic map. In this way, co-localisations with QTLs for phenotypic traits related to leaf or ear growth and development, biomass production and grain yield can be identified in both vegetative and reproductive organs [1,57]. Validation of these candidate genes exhibiting a strong alteration in their level of expression and co-localizing with phenotypic QTLs can then be undertaken using transgenic technologies, mutagenesis, or by association genetics, either at the single gene or genome-wide level.

\section{Methods}

Plant material

Maize wild type (WT) plants, (Zea mays L., genotype B73) and $g \ln 1.3$ and $g \ln 1.4$ mutant seeds in the B73 background (see [13], for the production, selection and characterization of the mutants) were grown as described in [18] in a glasshouse at the Institut National de la Recherche Agronomique, Versailles, France from May to September 2004. Three individual plants of similar size and of similar developmental stage were selected. They correspond to the three replicates used for the three different "omics" experiments. At the 10 to 11 leaf stage (45 days after sowing), the three entire youngest fully expanded leaves without the midrib were harvested and pooled as the vegetative stage (V) samples. The entire leaf below the ear without the midrib was harvested at 55 days after silking, corresponding to $65-70 \%$ of the grain filling stage and named the mature leaf developmental stage $(\mathrm{M})$. At this $\mathrm{M}$ stage of plant development, the leaf chlorophyll content was approximately $30 \%$ lower compared to that determined at silking, which corresponds to an early stage of leaf senescence [18]. Under our experimental conditions, maturity of the ear was attained around 80 days after silking.

In the glasshouse, plants were watered several times a day with a complete nutrient solution containing $10 \mathrm{mM}$ $\mathrm{KNO}_{3}$ as the sole $\mathrm{N}$ source [71]. The complete nutrient 
solution also contained $1.25 \mathrm{mM} \mathrm{K}^{+}, 0.25 \mathrm{mM} \mathrm{Ca}^{2+}$, $0.25 \mathrm{mM} \mathrm{Mg}^{2+}, 1.25 \mathrm{mM} \mathrm{H}_{2} \mathrm{PO}_{4}^{-}, 0.75 \mathrm{mM} \mathrm{SO}_{4}^{2-}, 21.5 \mu \mathrm{M}$ $\mathrm{Fe}^{2+}$ (Sequestrene; Ciba-Geigy, Basel, Switzerland), $23 \mu \mathrm{M} \mathrm{B}^{3+}$, $9 \mu \mathrm{M} \mathrm{Mn}^{2+}, 0.3 \mu \mathrm{M} \mathrm{Mo}^{2+}, 0.95 \mu \mathrm{M} \mathrm{Cu}^{2+}$, and $3.5 \mu \mathrm{M}$ $\mathrm{Zn}^{2+}$.

\section{RNA preparation}

Total RNA was extracted as described in [72] from leaves that had been stored at $-80^{\circ} \mathrm{C}$. Total RNAs $(50 \mu \mathrm{g})$ for transcriptome and quantitative Real Time-Polymerase Chain Reaction (qRT-PCR) studies were treated and prepared as previously described by [18]. Reverse transcription reactions and quantitative first strands were synthesized according to [18]. Primers for qRT-PCR and RT-PCR cloning were designed from Bacterial Artificial Chromosomes (BAC) sequences found in the public maize genome databases (Maizesequence.org, PlantGDB, Genebank). The sequences of the primers used in RT-PCR and qRT-PCR are presented in Additional file 1: Table S14.

\section{Gene expression profiles using maize cDNA microarrays and statistical analysis of data}

Whole genome leaf transcript profiling was performed using the maize $46 \mathrm{~K}$ arrays obtained from the maize oligonucleotide array project (http://www.maizegdb.org/ microarray.php\#mes) essentially as described previously in [18]. The maize $46 \mathrm{~K}$ spotted oligonucleotide array contains 46,000 unique probes from maize. Its detailed description, composition and gene putative annotation can be found at the Gene Expression Omnibus (GEO); (http:// www.ncbi.nlm.nih.gov/geo/query/acc.cgi?acc=GPL6438).

Starting with $3 \mu \mathrm{g}$ of total leaf RNA, non-modified amplified antisense RNA (aRNA) products were prepared using the Amino Allyl MessageAmp ${ }^{\mathrm{Tm}}$ aRNA Kit (Ambion, Foster City, CA, USA). Following this, $2 \mu \mathrm{g}$-aliquots of aRNA were labelled using the SuperSript ${ }^{\mathrm{TM}}$ Indirect $_{\mathrm{c}}$ DNA Labeling System Kit (Invitrogen, Carlsbad, CA, USA) and the purification steps were carried out using QIAquick ${ }^{\odot}$ PCR columns (QIAGEN, Hilden, Germany). The quantity and quality of each intermediate product, including total RNA, dscDNA, aRNA and labelled targets, were evaluated using a Nanodrop ND-1000 spectrophotometer and an Agilent Technologies 2100 Bioanalyzer. Hybridisations between the maize oligonucleotide microarrays and fluorescently labelled samples were performed in MICROMAX Hybridisation Buffer III (Perkin Elmer) using the manufacturer's hybridisation and wash conditions and a GeneTac ${ }^{\mathrm{Ts}}$ HybStation (Genomic Solutions, Ann Arbor, NI, USA). Before hybridisation, 50 pmol Cy3- and 50 pmol Cy5labelled targets were mixed, dried using compressed air and reconstituted with $115 \mu$ l of hybridisation buffer, followed by denaturing at $90^{\circ} \mathrm{C}$ for $3 \mathrm{~min}$. Each hybridisation mixture was placed on the maize $46 \mathrm{~K}$ array slides mounted in the hybridisation station and the hybridisations were performed for $3 \mathrm{~h}$ at $65^{\circ} \mathrm{C}$, followed by $3 \mathrm{~h}$ at $55^{\circ} \mathrm{C}$, then $12 \mathrm{~h}$ at $50^{\circ} \mathrm{C}$ with gentle agitation. Thereafter, the arrays were automatically washed with the GeneTac ${ }^{\mathrm{TM}}$ washing solutions (Genomic Solutions, Ann Arbor, NI, USA) using the program for multiple automatic washes, with a flow time of $40 \mathrm{~s}$. Hybridised microarrays were scanned using a GenePix 4000B Microarray Scanner (Molecular Devices, Sunnyvale, CA, USA) at $10-\mu \mathrm{m}$ resolution and variable photomultiplier (PMT) voltage to obtain maximal signal intensities with $<0.05 \%$ probe saturation. Subsequent image analysis was performed with the GenePix Pro (v6.0.1.26) software.

The transcript abundance of each of the 46, 000 unique genes in each of the three replicates for $\mathrm{V}$ and $\mathrm{M}$ leaves was determined using a mixture of all the samples (18 in total, each with the same mRNA concentration) as a reference. Statistical group comparisons were performed using multiple testing procedures to evaluate statistical significance for differentially expressed genes essentially as described in [18]. Transcriptomic data were validated by qRT-PCR analysis performed on a selected number of gene transcripts up- or down-regulated (Additional file 1: Figure S1). Non-filtered transcriptome data are presented in Additional files 2, 3, 4 and 5.

\section{Two-dimensional electrophoresis, gel staining, image analysis and protein identification}

Total protein extraction, solubilisation, and quantification were performed as described in [73]. The frozen leaf powder $(100 \mathrm{mg})$ was resuspended in acetone with $0.07 \%(\mathrm{v} / \mathrm{v})$ 2-mercaptoethanol and 10\% (w/v) TCA. Proteins were allowed to precipitate for $1 \mathrm{~h}$ at $-20^{\circ} \mathrm{C}$. The pellet was then washed overnight with acetone containing $0.07 \%$ (v/ v) 2-mercaptoethanol. Protein resolubilisation was performed using $60 \mu \mathrm{L} / \mathrm{mg}$ of R2D2 buffer (5 M urea, $2 \mathrm{M}$ thiourea, 2\% CHAPS, 2\% SB3-10, 20 mM dithiothreitol, $5 \mathrm{mM}$ Tris (2-carboxyethyl) phosphine hydrochloride, $0.75 \%$ carrier ampholytes). The total protein content of each sample was evaluated using the 2-D Quant kit (Amersham Biosciences).

Solubilised proteins $(300 \mu \mathrm{g})$ were separated on a $\mathrm{pH}$ 4-7 gradient Immobilised pH Gradient (IPG) strip (Amersham Biosciences) using a Protean Isoelectrofocusing (IEF) cell (Bio-Rad), as follows: Active rehydration was performed at $20^{\circ} \mathrm{C}$ for $13 \mathrm{~h}$ at $50 \mathrm{~V}$; then the focusing itself was carried out. After IEF, strips were equilibrated to improve protein transfer to the two-dimensional gel (2-D gel). The second separation was performed in an 11\% SDS-PAGE gel. Separation was carried out at $20 \mathrm{~V}$ for $1 \mathrm{~h}$ and subsequently at a maximum of $30 \mathrm{~mA} /$ gel, $120 \mathrm{~V}$ overnight, until the bromophenol blue front had reached the end of the gel. After SDS-PAGE, the gels were subsequently stained with colloidal Coomassie blue. Scanning was carried out at $300 \mathrm{dpi}$ with a 16-bit greyscale pixel depth using an image scanner 
(Amersham Biosciences), and then gel images were analyzed using the Progenesis and SameSpot softwares (Nonlinear Dynamics Ltd). The SAS package (procedure GLM for one way ANOVA analysis) was used to examine modifications of individual protein spot volumes. A protein spot was selected if its variation had a $\mathrm{p}$ value $<0.05$.

Spot digestion and LC-MS/MS were performed as described in [13]. In-gel digestion was performed with the Progest system (Genomic Solution). Gel pieces were washed twice by successive separate baths of $10 \%$ acetic acid, $40 \%$ ethanol, and acetonitrile (ACN). The pieces were then washed twice with successive baths of $25 \mathrm{mM}$ $\mathrm{NH}_{4} \mathrm{CO}_{3}$ and $\mathrm{ACN}$. Digestion was subsequently performed for $6 \mathrm{~h}$ at $37^{\circ} \mathrm{C}$ with $125 \mathrm{ng}$ of modified trypsin (Promega) dissolved in $20 \%$ methanol and $20 \mathrm{mM} \mathrm{NH}_{4} \mathrm{CO}_{3}$. The peptides were extracted successively with $2 \%$ trifluoroacetic acid (TFA) and 50\% ACN and then with ACN. Peptide extracts were dried in a vacuum centrifuge and suspended in $20 \mathrm{~mL}$ of $0.05 \%$ TFA, $0.05 \%$ formic acid and $2 \%$ ACN. HPLC was performed on an Ultimate LC system combined with a Famos Autosampler and a Switchos II microcolumn switch system (Dionex). A multiple-threshold filter was applied at the peptide level: Xcorr magnitude were up to 1.7, 2.2, 3.3 and 4.3 for peptides with one, two, three and four isotopic charges respectively; peptide probability lower than $0.05, \Delta \mathrm{Cn}>0.1$ with a minimum of two different peptides for an identified protein. A database search was performed with Bioworks 3.3.1 (Thermo Electron). The TIGR maize gene indice database v 16, 72047*6 EST (http:// maize.jcvi.org/) sequences was used.

\section{Metabolome analysis}

All steps were adapted from the original protocol described in [74] following the procedure described in [18]. The ground frozen leaf samples (25 $\mathrm{mg}$ fresh weight) were resuspended in $1 \mathrm{ml}$ of frozen $\left(-20^{\circ} \mathrm{C}\right)$ Water: Chloroform: Methanol (1:1:2.5) and extracted for $10 \mathrm{~min}$ at $4^{\circ} \mathrm{C}$ with shaking at $1400 \mathrm{rpm}$ in an Eppendorf Thermomixer. Insoluble material was removed by centrifugation and $900 \mu \mathrm{l}$ of the supernatant were mixed with $20 \mu \mathrm{l}$ of $200 \mu \mathrm{g} / \mathrm{ml}$ ribitol in methanol. Water $(360 \mu \mathrm{l})$ was then added and after mixing and centrifugation, $50 \mu \mathrm{l}$ of the upper polar phase were collected and dried for $3 \mathrm{~h}$ in a Speed-Vac and stored at $-80^{\circ} \mathrm{C}$. For derivatisation, samples were removed from $-80^{\circ} \mathrm{C}$ storage, warmed for $15 \mathrm{~min}$ before opening and Speed-Vac dried for $1 \mathrm{~h}$ before the addition of $10 \mu \mathrm{l}$ of $20 \mathrm{mg} / \mathrm{ml}$ methoxyamine in pyridine. The reactions with the individual samples, blanks and amino acid standards were performed for $90 \mathrm{~min}$ at $28^{\circ} \mathrm{C}$ with continuous shaking. $90 \mu \mathrm{l}$ of $\mathrm{N}$-methyl-N-trimethylsilyl-trifluoroacetamide (MSTFA) were then added and the reaction continued for $30 \mathrm{~min}$ at $37^{\circ} \mathrm{C}$. After cooling, $50 \mu \mathrm{l}$ of the reaction mixture were transferred to an Agilent vial for injection. For the analysis, $3 \mathrm{~h}$ and $20 \mathrm{~min}$ after derivatisation, $1 \mu \mathrm{l}$ of the derivatised samples were injected in the Splitless mode onto an Agilent 7890A gas chromatograph (GC) coupled to an Agilent 5975C mass spectrometer (MS). The column used was an Rxi-5SilMS from Restek (30 m with $10 \mathrm{~m}$ Integra-Guard column). The oven temperature ramp was $70^{\circ} \mathrm{C}$ for $7 \mathrm{~min}$, then $10^{\circ} \mathrm{C} / \mathrm{min}$ up to $325^{\circ} \mathrm{C}$, which was maintained for $4 \mathrm{~min}$. For data processing, Raw Agilent datafiles were converted into the NetCDF format and analyzed with AMDIS (http://chemdata. nist.gov/dokuwiki/doku.php?id=chemdata:amdis). Peak areas were then determined using the quanlynx software (Waters) after conversion of the NetCDF file into the masslynx format. Statistical analyses were carried out with TMEV http://www.tm4.org/index.html. Univariate analyses by permutation (1-way ANOVA and 2-way ANOVA) were first used to select the metabolites exhibiting significant changes in their concentration.

\section{Availability of supporting data}

The original transcriptomic data sets are presented in supplementary file 16 to 19 . Proteomic and metabolomic data sets can be obtained from the corresponding author on request.

\section{Additional files}

Additional file 1: Table S1. Metabolites exhibiting significant changes in their concentration at the $\mathrm{V}$ and $\mathrm{M}$ stage in $g \ln 1.3$ and $g \ln 1.4$ mutants. Table S2. Proteins exhibiting significant decrease (a) and increase (b) in their concentration in the gln 1.3 mutant at the $V$ stage. Table S3. Proteins exhibiting significant decrease (a) and increase (b) in their concentration in the gln 1.3 mutant at the M stage. Table S4. Proteins exhibiting significant decrease (a) and increase (b) in their concentration in the gln 1.4 mutant at the $V$ stage. Table S5. Proteins exhibiting significant decrease (a) and increase (b) in their concentration in the gln1.4 mutant at the M stage. Table S6. Transcripts exhibiting significant decrease (a) and increase (b) in their concentration in the gln 1.3 mutant at the $V$ stage. Table S7. Transcripts exhibiting significant decrease (a) and increase (b) in their concentration in the gln 1.3 mutant at the M stage. Table S8. Transcripts exhibiting significant decrease (a) and increase (b) in their concentration in the gln 1.4 mutant at the $V$ stage. Table S9. Transcripts exhibiting significant decrease (a) and increase (b) in their concentration in the gln1.4 mutant at the M stage. Table S10. Transcripts exhibiting significant changes in gln 1.3 mutant both at the $V$ and M stage. Table S11. Transcripts exhibiting significant changes in gln1.4 mutant both at the $\mathrm{V}$ and $\mathrm{M}$ stage. Table S12. Transcripts exhibiting significant changes both in $g \ln 1.3$ and $g \ln 1.4$ mutant both at the $V$ stage. Table S13. Transcripts exhibiting significant changes both in gln 1.3 and $g \ln 1.4$ mutant both at the M stage. Table S14. Primers used in qRT-PCR for the validation of the transcriptome study. Figure S1. Transcript abundance in the $g \ln 1.3$ and $g \ln 1.4$ maize (Zea mays L.) mutants compared to the wild type (WT) of selected genes.

Additional file 2: Non-filtered transcriptome data obtained with the maize $46 \mathrm{k}$ oligonuceotide array for $g \ln 1.4$ mutant in comparison to the WT at the vegetative (V) stage.

Additional file 3: Non-filtered transcriptome data obtained with the maize $46 \mathrm{k}$ oligonuceotide array for $g \ln 1.3$ mutant in comparison to the WT at the maturity (M) stage. 
Additional file 4: Non-filtered transcriptome data obtained with the maize $46 \mathrm{k}$ oligonuceotide array for $g \ln 1.3$ mutant in comparison to the WT at the vegetative (V) stage.

Additional file 5: Non-filtered transcriptome data obtained with the maize $46 \mathrm{k}$ oligonuceotide array for $g \ln 1.4$ mutant in comparison to the WT at the maturity (M) stage.

\section{Abbreviations}

C: Carbon; 2-D: Two dimentional electrophoresis; GC/MS: Gas chromatography coupled to mass spectrometry; GS: Glutamine synthetase; M: Maturity stage; N: Nitrogen; NUE: Nitrogen use efficiency; QTLs: Quantitative trait loci; TCA: Tricarboxylic acid; V: Vegetative stage; WT: Wild type.

\section{Competing interest}

The authors declare that they have no competing interests.

\section{Authors' contributions}

$\mathrm{NA}^{1}, \mathrm{BH}, \mathrm{SI}, \mathrm{MZ}$ and $\mathrm{IO}$ conceived the study, $\mathrm{NA}^{1}$ conducted the proteomic and transcriptomic experiments and analysed omics data, SI and NA ${ }^{2}$ participated in the transcriptomic analysis, BV identified proteins by mass spectrometry, TB helped in the 2D electrophoresis, GC performed the metabolomic study and TTL the qRT-PCR experiments. IQ and CDG were in charge of plant production, samples harvesting, characterization and preparation before "omic" analysis. All authors read and approved the final manuscript.

\section{Acknowledgments}

We thank Prof. P.J. Lea, Prof. Lawrence Aggerbeck, Rajib Saha and Margaret Simons for their helpful comments on the manuscript. This project was supported by the ANR-Genoplante program Maize and Yield (GNP05015G).

\section{Author details}

'Institut Jean-Pierre Bourgin, Institut National de la Recherche Agronomique (INRA), Centre de Versailles-Grignon, Unité Mixte de Recherche 1318 INRA-Agro-ParisTech, Equipe de Recherche Labellisée, Centre National de la Recherche Scientifique 3559, RD10, F-78026 Versailles, Cedex, France. ${ }^{2}$ Centre de Génétique Moléculaire, Unité Propre de Recherche 2167, Centre National de la Recherche Scientifique and, Gif/Orsay DNA MicroArray Platform (GODMAP), 1, avenue de la Terrasse, F-91198, Gif sur Yvette Paris, France. ${ }^{3}$ Platerforme d'Analyse Protéomique de Paris Sud-Ouest, Unité Mixte de Recherche de Génétique Végétale, Ferme du Moulon, F-91190, Gif/Yvette, Paris, France. ${ }^{4}$ Sorbonne Universités, Université Pierre et Marie Curie, Université de Paris 06, Unité Mixte de Recherche 7238, Biologie Computationnelle et Quantitative, F-75006 Paris, France. ${ }^{5}$ Centre National de la Recherche Sceintifique, Unité Mixte de Recherche 7238, Biologie Computationnelle et Quantitative, F-75006 Paris, France.

Received: 19 June 2014 Accepted: 4 November 2014 Published: 20 November 2014

\section{References}

1. Hirel B, Le Gouis J, Ney B, Gallais A: The challenge of improving nitrogen use efficiency in crop plants: towards a more central role for genetic variability and quantitative genetics within integrated approaches. J Exp Bot 2007, 58:2369-2387.

2. Good AG, Beatty PH: Fertilizing nature: a tragedy of excess in the commons. PLoS Biol 2011, 9:e1001124

3. Andrews M, Lea PJ: Our nitrogen footprint: the need for increased crop nitrogen use efficiency. Ann Appl Biol 2013, 163:165-169.

4. Bertin P, Gallais A: Physiological and genetic basis of nitrogen use efficiency in maize.II. QTL detection and coincidences. Maydica 2001, 46:53-68.

5. Gallais A, Hirel B: An approach of the genetics of nitrogen use efficiency in maize. J Exp Bot 2004, 55:295-306.

6. Wang L, Zhong M, Li X, Yuan D, Xu Y, Liu H, He Y, Luoi L, Zhang Q: The QTL controlling amino acid content in grains of rice (Oryza sativa) are co-localized with the regions involved in the amino acid metabolism pathway. Mol Breed 2008, 21:127-137.
7. Xie HL, Ji HQ, Liu Z, Tian GW, Wang CL, Hu YM, Tang JH: Genetic basis for nutritional content of stover in maize under low nitrogen conditions. Euphytica 2009, 165:485-493

8. Cai H, Chu Q, Gu R, Yuan L, Liu J, Zhang X, Chen F, Mi G, Zhang F: Identification of QTLs for plant height, ear height and grain yield in maize (Zea mays L.) in response to nitrogen and phosphorus supply. Plant Breed 2012, 131:502-510.

9. Liu R, Zhang H, Zhao P, Zhang Z, Liang W, Tian Z, Zheng Y: Mining of candidate maize genes for nitrogen use efficiency by integrating gene expression and QTL data. Plant Mol Biol Rep 2012, 30:297-308.

10. Hirel B, Bertin P, Quillere I, Bourdoncle W, Attagnant C, Dellay C, Gouy A, Cadiou S, Retailliau C, Falque M, Gallais A: Towards a better understanding of the genetic and physiological basis for nitrogen use efficiency in maize. Plant Physiol 2001, 125:1258-1270.

11. Zhang N, Gibon Y, Gur A, Chen C, Lepak N, Höhne M, Zhang Z, Kroon D, Tschoep H, Stitt M, Buckler E: Fine quantitative trait loci mapping of carbon and nitrogen metabolism enzyme activities and seedling biomass in the maize IBM mapping population. Plant Physiol 2010, 154:1753-1765.

12. Wen W, Li D, Li X, Gao Y, Li W, Li H, Liu J, Liu H, Chen W, Luo J, Yan J: Metabolome-based genome wide association study of maize kernel leads to novel biochemical insights. Nat Commun 2014, 5:3438. doi:10.1038/ncoms4438.

13. Martin A, Lee J, Kichey T, Gerentes D, Zivy M, Tatou C, Balliau T, Valot B, Davanture M, Dubois F, Tercé-Laforgue T, Coque M, Gallais A, GonzalezMoro MB, Bethencourt L, Quilleré I, Habash DZ, Lea PJ, Charcosset A, Perez P, Murigneux A, Sakakibara H, Edwards KJ, Hirel B: Two cytosolic glutamine synthetase isoforms of maize (Zea mays L.) are specifically involved in the control of grain production. Plant Cell 2006, 18:3252-3274.

14. Obara M, Kajiura M, Fukuta $Y$, Yano M, Hayashi M, Yamaya T, Sato T: Mapping of QTLs associated with cytosolic glutamine synthetase and NADH-glutamate synthase in rice (Oryza sativa L.). J Exp Bot 2001, 52:1209-1217

15. Tabuchi M, Sugiyama T, Ishiyama K, Inoue E, Sato T, Takahashi H, Yamaya T: Severe reduction in growth and grain filling of rice mutants lacking OsGS1;1, a cytosolic glutamine synthetase 1;1. Plant J 2005, 42:641-655.

16. Hirel B, Martin Tercé-Laforgue T, Gonzalez-Moro MB, Estavillo JM: Physiology of maize I: A comprehensive and integrated view of nitrogen metabolism in a $C_{4}$ plant. Physiol Plant 2005, 124:167-177.

17. Fritz C, Palacios-Rojas NP, Feil R, Stitt M: Regulation of secondary metabolism by the carbon-nitrogen status of tobacco: nitrate inhibits large sectors of phenylpropanoid metabolism. Plant J 2006, 46:533-548.

18. Amiour N, Imbaud S, Clement G, Agier N, Zivy M, Valot B, Balliau T, Armengaud P, Quilleré I, Cañas RA, Tercé-laforgue T, Hirel B: The use of metabolomics integrated with transcriptomic and proteomic studies for identifying key steps involved in the control of nitrogen metabolism in crops such as maize. J Exp Bot 2012, 63:5017-5033.

19. Loewus FA, Murthy PN: Myo-inositol metabolism in plants. Plant Sci 2000 150:1-19.

20. Stoop JMH, Williamson JD, Pharr DM: Mannitol metabolism in plants: a method for coping with stress. Trends Plant Sci 1996, 1:139-144.

21. Taji T, Ohsumi C, luchi S, Deki M, Seki M, Kasuga M, Kobayashi M, Yamaguchi-Shinozaki K, Shinozaki K: Important roles of drought- and cold-inducible genes for galactinol synthase in stress tolerance in Arabidopsis thaliana. Plant J 2002, 29:417-426

22. Miret JA, Munné-Bosch S: Plant amino acid-derived vitamins: biosynthesis and function. Amino Acids 2013, 46:809-824

23. Li J, Copeland L: Role of malonate in chickpeas. Phytochemistry 2000 , 54:585-589.

24. Engqvist MKM, Khun A, Wienstroer J, Weber K, Jansen EEW, Jakobs C, Weber APM, Maurino VG: Plant D-2-hydroxyglutarate dehydrogenase participates in the catabolism of lysine especially during senescence. J Biol Chem 2011, 286:11382-11390.

25. Olivier RA, Bedgar DL, Davin LB, Lewis NG: The arogenate dehydratase gene family: towards understanding differential regulation of carbon flux through phenylalanine into primary versus secondary metabolic pathways. Phytochemistry 2012, 82:22-37.

26. Boerjan W, Ralph J, Baucher M: Lignin biosynthesis. Annu Rev Plant Biol 2003, 54:519-546.

27. Seebauer JR, Moose SP, Fabbri BJ, Crossland LD, Below FE: Amino acid metabolism in maize ear shoots. Implications for assimilate preconditioning and nitrogen signalling. Plant Physiol 2004, 136:4326-4334. 
28. Hancock RD, Morris WL, Ducreux LJM, Morris JA, Usman M, Verrall SR, Fuller JF, Simpson GG, Zhang R, Hedley PE, Taylor MA: Physiological, biochemical and molecular response of the potato (Solanum tuberosum L.) plant to moderately elevated temperature. Plant Cell Environ 2014, 37:439-450.

29. Below FE, Cazetta JO, Seebauer JR: Carbon/Nitogen interactions during ear and kernel development of maize. In Physiology and Modelling Kernel Set in Maize, Volume 29. Edited by Westgate ME, Boote KJ. Madison, Wl: Crop Science Society of American and American Society of Agronomy; 2000:15-24

30. Seebauer JR, Singletary GW, Krumpelman M, Ruffo ML, Below FE: Relationship of source and sink in determining kernel composition in maize. J Exp Bot 2010, 61:511-519.

31. Schnarrenberger C, Flechner A, Martin W: Enzymatic evidence for a complete oxidative pentose phosphate pathway in chloroplasts and an incomplete pathway in the cytosol of spinach leaves. Plant Physiol 1995, 108:609-614.

32. Furbank RT, Taylor WC: Regulation of photosynthesis in $C_{3}$ and $C_{4}$ plants: a molecular approach. Plant Cell 1995, 7:797-807.

33. Wang L, Li Y, Jacquot JP, Rouhier N, Xia B: Characterization of poplar GrxS14 in different structural forms. Protein Cell 2014, doi:10.1007/s13238-014-0042-3.

34. Dietz KJ, Jacob S, Oelze ML, Laxa M, Tognetti V, Nunes de Miranda SM, Baier $M$, Finkemeir l: The function of peroxiredoxins in plant organelle redox metabolism. J Exp Bot 2011, 57:1697-1709.

35. Gutu A, Nesbit AD, Alverson AJ, Palmer JD, Kehoe DM: Unique role for translation initiation factor 3 in the light color regulation of photosynthetic gene expression. Proc Natl Acad Sci U S A 2013, 110:16253-16258

36. Russel DA, Sachs MM: Differential expression and sequence analysis of the maize glyceraldehyde-3-phosphate dehydrogenase gene family. Plant Cell 1989, 1:793-803.

37. Hussain SS, Ali M, Ahmad M, Siddique KHM: Polyamines: natural and engineered abiotic and biotic stress tolerance in plants. Biotechnol Adv 2011, 29:300-311.

38. Simons M, Saha R, Guillard L, Clément G, Armengaud P, Cañas R, Maranas CD, Lea PJ, Hirel B: Nitrogen use efficiency in maize (Zea mays L.): from "omics" studies to metabolic modelling. J Exp Bot 2014, 65:5657-5671

39. Bahrman N, Le Gouis J, Negroni L, Amilhat L, Leroy P, Lainé AL, Jaminon O: Differential protein expression assessed by two-dimensional gel electrophoresis for two wheat varieties grown at four nitrogen regimes. Proteomics 2004, 4:709-719.

40. Prinsi B, Negri AS, Pesaresi $P$, Cocucci M, Espen L: Evaluation of protein pattern changes in roots and leaves of Zea mays plants in response to nitrate availability by two-dimensional gel electrophoresis analysis. BMC Plant Biol 2009, 9:113.

41. MØller ALB, Pedas P, Andersen B, Svensson B, Schoerring JK, Finnie C Responses of barley root and shoot proteomes to long-term nitrogen deficiency, short term nitrogen starvation and ammonium. Plant Cell Environ 2011, 34:2024-2037.

42. Tovar-Méndez A, Miernyk JA, Randall DD: Regulation of pyruvate dehydrogenase complex activity in plant cells. Eur J Biochem 2003, 270:1043-1049.

43. Vincent R, Fraisier V, Chaillou S, Limami MA, Deléens E, Phillipson B, Douat C, Boutin JP, Hirel B: Overexpression of a soybean gene encoding cytosolic glutamine synthetase in shoots of transgenic Lotus corniculatus L. plants triggers changes in ammonium assimilation and plant development. Planta 1997, 201:424-433.

44. Sato Y, Antonio B, Namiki N, Motoyama R, Sugimoto K, Takehisa H, Minmi H, Kamatsuki K, Kusababa M, Hirochika H, Nagamura Y: Field transcriptome revealed critical developmental and physiological transitions involved in the expression of growth potential in japonica rice. BMC Plant Biol 2011, 11:10.

45. Shen $Y$, Venu RC, Nobuta K, Wu X, Notibala V, Demirci C, Meyers BC, Wang GL, Ji G, Li QQ: Transcriptome dynamics through alternative polyadenylation in developmental environmental responses in plants revealed by deep sequencing. Genome 2011, 21:1478-1486.

46. Hoppe A: What mRNA abundances can tell us about metabolism. Metabolites 2012, 2:614-631.

47. Fernie AR, Stitt M: On the discordance of metabolomics with proteomics and transcriptomics: coping with increasing complexity in logic, chemistry and network interaction. Plant Physiol 2012, 158:1139-1145.

48. Wei K, Chen J, Wang Y, Chen Y, Chen S, Lin Y, Pan S, Zhong X, Xie D Genome-wide analysis of bZIP-encoding genes in maize. DNA Res 2012, 19:463-476.
49. Li XP, Björkman O, Shih C, Crossman AR, Rosenquist M, Jansson S, Niyogi KK: A pigment-binding protein essential for regulation of photosynthetic light harvesting. Nature 2010, 403:391-395.

50. Takahashi S, Badger M: Photoprotection in plants: a new light on photosystem II damage. Trends Plant Sci 2011, 16:53-60

51. Senger B, Auxilien S, Englisch, Cramer F, Fasiolo F: The modified wobble base inosine in yeast tRNA is a positive determinant for aminoacylation by isoleucyl-tRNA synthetase. Biochemistry 1997, 36:8269-8275.

52. Taniguchi T, Miyaushi K, Nakane D, Miyata M, Muto A, Nishimura S, Suzuki T: Decoding system for the UAU codon tRNAlle with the UAU anticodon in Mycoplasma mobile. Nucleic Acids Res 2013, 41:2621-2631.

53. Slewinski TL: Diverse functional roles of monosaccharide transporters and their homologs in vascular plants: a physiological perspective. Mol Plant 2011, 4:641-662.

54. Gupta S, Gallavotti G, Stryker GA, Schmidt RJ, Lal SK: A novel class of Helitron-related transposable element in maize contain portions of multiple pseudogenes. Plant Mol Biol 2005, 57:115-127.

55. Schuler MA, Werck-Reichart D: Functional genomics of P450s. Annu Rev Plant Biol 2003, 54:629-667.

56. Broyart $C$, Fontaine J-X, Molinié R, Cailleu D, Tercé-Laforgue T, Dubois F, Hirel B, Mesnard F: Metabolic profiling of maize mutants deficient for two glutamine synthetase isoenzymes using 1H-NMR-based metabolomics. Phytochem Anal 2010, 21:102-109.

57. Cañas RA, Quilleré I, Lea PJ, Hirel B: Analysis of amino acid metabolism in the ear of maize mutants deficient in two cytosolic glutamine synthetase isoenzymes highlights the importance of asparagine for nitrogen translocation within sink organs. Plant Biotechnol J 2010, 8:966-978.

58. Shen H, Mazarei M, Hisano H, Escamilla-Trevino L, Fu C, Pu Y, Rudis MR, Tang Y, Xiao X, Jackson L, Li G, Hernandez T, Chen F, Ragauskas AJ, Neal Stewart C Jr, Wang $Z Y$, Dixon RA: A genomic approach to deciphering lignin biosynthesis in switchgrass. Plant Cell 2013, 25:4342-4361.

59. Minic Z: Physiological role of plant glycoside hydrolases. Planta 2008, 227:723-740.

60. Kasprzewska A: Plant chitinase-regulation and function. Cell Mol Biol Lett 2003, 8:809-824.

61. Zhao Y, Dong W, Zhang N, Ai X, Wang M, Huang Z, Xiao L, Xia G: A wheat allene oxide cyclase gene enhances salinity tolerance via jasmonate signalling. Plant Physiol 2013, 164:1068-1076.

62. Maris $C$, Dominguez $C$, Allain FHT: The RNA recognition motif, a plastic RNA-binding platform to regulate post-transcriptional gene expression. FEBS J 2005, 272:2118-2131.

63. Fontaine JX, Tercé-Laforgue $T$, Armengaud P, Clément G, Renou JP, Pelletier S, Catterou M, Azzopardi M, Gibon Y, Lea PJ, Hirel B, Bubois F: Characterization of a NADH-dependent glutamate dehydrogenase mutant of Arabidopsis demonstrates the key role of this enzyme in root carbon and nitrogen metabolism. Plant Cell 2012, 24:4044-4065.

64. Andrews M, Raven JA, Lea PJ: Do plants need nitrate? The mechanisms by which nitrogen form affects plants. Ann App/ Biol 2013, 163:174-199.

65. Dauwe R, Moreel K, Goemine G, Gielen, Rohde A, Van Beeumen J, Ralph J, Boudet AM, Kopka J, Rochange SF, Halpin C, Messens E, Boerjan W: Molecular phenotyping of lignin-modified tobacco reveals associated changes in cell-wall metabolism, primary metabolism, stress metabolism and photorespiration. Plant J 2007, 52:263-285.

66. Hirai M, Yano M, Goodenove DB, Kanaya S, Kimura T, Awazuhara M, Fujiwara $T$, Saito: Integration of transcriptomics and metabolomics for understanding of global responses to nutritional stresses in Arabidopsis thaliana. Proc Natl Acad Sci U S A 2004, 101:10205-12010.

67. Kant SK, Bi YM, Rothstein S: Understanding plant response to nitrogen limitation for the improvement of crop nitrogen use efficiency. J Exp Bot 2011, 62:1400-1509.

68. Gutiérrez RA: Systems biology for enhanced plant nitrogen nutrition Science 2012, 336:1673-1675.

69. Kruger NJ, Ratcliffe RG: Pathways and fluxes: exploring the plant metabolic network. J Exp Bot 2012, 63:2243-2246.

70. Ruppin E, Papin JA, de Figueiredo LF, Schuster S: Metabolic reconstruction, constraint-based analysis and game theory to probe genome-scale metabolic networks. Curr Opin Biotechnol 2010, 21:502-510.

71. Coï $Y$, Lesaint $C$ : Comment assurer une bonne nutrition en eau et en ions minéraux en horticulture. Horticulture Française 1971, 8:11-14.

72. Verwoerd TC, Dekker BNM, Hoekema A: A small-scale procedure for the rapid isolation of plants RNAs. Nucleic Acids Res 1989, 17:2362. 
73. Méchin V, Thévenot C, Le G, Prioul JL, Damerval C: Developmental analysis of maize endosperm proteome suggests a pivotal role for pyruvate orthophosphate dikinase. Plant Physiol 2007, 143:1203-1219.

74. Fiehn O: Metabolite profiling in Arabidopsis. In Methods in Molecular Biology. 2nd edition. Edited by Salinas J, Sanchez-Serrano JJ. Totowa NJ: Humana Press; 2006:439-447.

doi:10.1186/1471-2164-15-1005

Cite this article as: Amiour et al: An integrated "omics" approach to the characterization of maize (Zea mays $L$.) mutants deficient in the expression of two genes encoding cytosolic glutamine synthetase. BMC Genomics 2014 15:1005.

\section{Submit your next manuscript to BioMed Central and take full advantage of:}

- Convenient online submission

- Thorough peer review

- No space constraints or color figure charges

- Immediate publication on acceptance

- Inclusion in PubMed, CAS, Scopus and Google Scholar

- Research which is freely available for redistribution 